\title{
THE ROTATIONAL EMISSION-LINE SPECTRUM OF ORION A BETWEEN 247 AND 263 GHZ
}

\author{
GEOFFREY A. BLAKE ${ }^{1}$ \\ Department of Chemistry, California Institute of Technology \\ E. C. SutTon \\ Space Sciences Laboratory, University of California, Berkeley \\ AND \\ C. R. Masson and T. G. Phillips \\ Department of Physics, California Institute of Technology \\ Received 1985 May 23; accepted 1985 July 15
}

\begin{abstract}
Results are presented from a molecular line survey of the core of the Orion molecular cloud between 247 and $263 \mathrm{GHz}$. The spectrum contains a total of 243 resolvable lines from 23 different chemical species. When combined with the earlier survey of Orion from 215 to $247 \mathrm{GHz}$ by Sutton et al. (1985), the complete data set includes over 780 emission features from 29 distinct molecules. Of the 23 molecules detected in this survey, only $\mathrm{NO}, \mathrm{CCH}$, and $\mathrm{HCO}^{+}$were not identified in the lower frequency data.

As a result of the supporting laboratory spectroscopy performed to supplement existing millimeter-wave spectral line catalogs, only 33 of the more than 780 lines remain unidentified, of which 16 occur in the upper frequency band. A significant chance remains that a number of these unidentified lines are due to transitions between states of either isotopically substituted or highly excited abundant and complex molecules such as $\mathrm{CH}_{3} \mathrm{OH}, \mathrm{CH}_{3} \mathrm{OCH}_{3}$, and $\mathrm{HCOOCH}_{3}$, whose rotational spectra are poorly known at present. The very small percentage and weak strength of the unidentified lines implies that the dominant chemical constituents visible at millimeter wavelengths have been identified in the Orion molecular cloud.
\end{abstract}

Subject headings: interstellar: molecules - line identifications - nebulae: Orion Nebula

\section{INTRODUCTION}

Recent advances in telescope design and receiver performance at millimeter wavelengths have greatly improved our understanding of the physical and chemical composition of interstellar molecular clouds. It is only recently that we have begun to understand how molecules can be created so effciently in such a hostile environment, and why in some cases the chemical compositions of the various types of interstellar clouds should differ so radically. By observing the rotational spectra of numerous molecular species, we are now in a position to examine in detail the intricate reaction pathways which are responsible for maintaining the rich chemical diversity of the interstellar medium. Whereas only limited observations of selected species were previously possible, the improved sensitivity of new instruments has allowed unbiased surveys of molecular line emission to be conducted on a number of objects. For example, Johansson et al. (1984) have surveyed emission from both Orion A and IRC +10216 between 73 and $91 \mathrm{GHz}$ and report the detection of 170 and 45 lines, respectively, from these two objects, while Cummins, Linke, and Thaddeus (1986) have made a somewhat broader line search of Sgr B2 from 70 to $145 \mathrm{GHz}$, detecting some 457 individual emission lines.

\footnotetext{
${ }^{1}$ Current address: Space Sciences Laboratory, University of California, Berkeley.
}

We have previously presented a spectral line survey of Orion A between 215 and $247 \mathrm{GHz}$ performed at the Owens Valley Radio Observatory (Sutton et al. 1985, hereafter Paper I), in which over 500 resolvable lines from 25 distinct chemical species were identified. The higher excitation requirements of rotational transitions at near-millimeter wavelengths combined with the small telescope beamwidth made this line survey particularly sensitive to emission from the active core of the Orion molecular cloud, and were responsible, in part, for the increased density and strength of the rotational line emission in Paper I as compared with the lower frequency studies noted above.

As part of a continuing effort in this laboratory to characterize accurately the physical and chemical nature of the dense interstellar gas, we present here the results of a molecular line survey of Orion A between 247 and $263 \mathrm{GHz}$. These observations complement the earlier work conducted on Orion, and were obtained in part to include the stronger rotational transitions of linear triatomic species such as $\mathrm{HCN}$ and $\mathrm{HCO}^{+}$ that were not included in the lower frequency survey. Also included in this frequency band are the $J=5 / 2-3 / 2$ transitions of NO, the $N=3-2$ lines of $\mathrm{CCH}$ and $\mathrm{HCO}$, and one of the strongest $\mathrm{CH}_{3} \mathrm{OH} Q$-branches below $300 \mathrm{GHz}$. A preliminary analysis of the higher frequency data has been used by Sutton et al. (1984) to deduce the spectral index of and absolute integrated flux from molecular line emission at milli- 
meter wavelengths. Their results indicate that rotational line emission may contribute substantially to the energy balance of molecular clouds, providing at least $40 \%$ of the measured broad-band flux at $1.3 \mathrm{~mm}$ in OMC-1.

Approximately 243 lines from 23 molecules have been identified in the present line search, which brings the total number of detected lines to over 780 in the complete survey, arising from 29 distinct chemical species. The average strength and density of the spectral lines is considerably higher in the upper frequency band, as is to be expected for thermalized emission emanating mainly from the warm, compact core of Orion A. As with the earlier survey, at least three distinct kinematic regions are clearly implied by the detected velocities and line widths, ranging from the quiescent and extended "ridge" or "spike" emission appearing at a $v_{\text {LSR }}$ of $\sim 9$ $\mathrm{km} \mathrm{s}^{-1}$ and characterized by line widths of $\leqslant 5 \mathrm{~km} \mathrm{~s}^{-1}$ to the more turbulent and compact "plateau" $\left(v_{\mathrm{LSR}} \sim 7-8 \mathrm{~km} \mathrm{~s}^{-1}\right.$, $\left.\Delta v \gtrsim 25 \mathrm{~km} \mathrm{~s}^{-1}\right)$ and "hot core" ( $v_{\mathrm{LSR}} \sim 3-5 \mathrm{~km} \mathrm{~s}^{-1}, \Delta v \lesssim$ 10-15 $\mathrm{km} \mathrm{s}^{-1}$ ) sources described by a number of previous authors (Zuckerman and Palmer 1975; Morris, Palmer, and Zuckerman 1980; Genzel et al. 1982; Johansson et al. 1984; Sutton et al. 1984; Paper I).

\section{OBSERVATIONS AND DATA ANALYSIS}

\section{a) Observations}

The observations were carried out with the $1.3 \mathrm{~mm}$ spectroscopy system of the Owens Valley Radio Observatory, and were centered on a nominal source position of $\alpha(1950)=$ $05^{\mathrm{h}} 32^{\mathrm{m}} 47^{\mathrm{s}}, \delta(1950)=-05^{\circ} 24^{\prime} 21^{\prime \prime}$. The $10.4 \mathrm{~m}$ telescope beam size was slightly under 0.5 throughout the $250-265 \mathrm{GHz}$ region. A superconducting tunnel junction (SIS) receiver (Sutton 1983), operated in the double-sideband mode with an IF center frequency of $1388 \mathrm{MHz}$, served as the front end and provided a noise temperature of about $700 \mathrm{~K}$ (single sideband), while a 512 channel acousto-optical spectrometer (AOS) similar to the described by Masson (1982) was used as the back end. The $1.03 \mathrm{MHz}$ AOS channel width yielded a resolution of $1.2 \mathrm{~km} \mathrm{~s}^{-1}$ at $250 \mathrm{GHz}$.

The raw double-sideband spectra reported here were recorded entirely during 1983 November, and were processed into a single-sideband spectrum with the "cleaning" procedure described in Paper I. Thirty-two double-sideband spectra from a total of eight nights were used in the data set. As a result of insufficient observing time, gaps near 249, 252, and $254 \mathrm{GHz}$ exist in the spectrum. The double-sideband spectra have been calibrated for telescopic and atmospheric losses using standard "chopper wheel" techniques. We estimate an uncertainty of approximately $\pm 15 \%$ for the corrected double-sideband data. As noted in Paper I, the cleaning procedure increases the accuracy of the overall calibration because each line is observed several times. The line brightness temperatures of the various Orion emission regions cannot be properly estimated using a single beam efficiency correction, however, because of their differing size. We have therefore established the final antenna temperature scale using the extended source efficiency of $\eta \sim 0.85$, derived from maps of the Moon. No corrections have been made for the beam dilution of spatially compact sources, such as the plateau and hot core components.

\section{b) Reduction to Single-Sideband Information}

By observing a large set of frequencies spaced closely enough so that each individual line is observed several times, it is possible to deconvolve the set of double-sideband spectra into one "cleaned" single-sideband spectrum. If the doublesideband data are taken by stepping the local oscillator by the full width of the back end, then each line will appear at most twice, once each in the upper and lower receiver sidebands. The data between 247 and $249 \mathrm{GHz}$ were collected in this manner, as was the lower frequency work (Paper I), namely, by stepping the local oscillator in $500 \mathrm{MHz}$ increments, although a number of additional scans were also recorded at intermediate local oscillator frequencies in the $215-247 \mathrm{GHz}$ interval. The disadvantage of this procedure is that large regions of the spectrum (at the two ends) were represented by only a single observation. Hence it was difficult to ensure good separation of the data from the two sidebands. Also, even in the center region lines were often observed only twice, which at times was insufficient when both instances were coincident with the lines in the opposite sidebands.

It quickly became obvious in the data analysis that a more densely spaced set of observations would be advantageous, particularly where the density of lines was expected to be high. Since this was expected to be especially true for the higher frequency band, spectra were spaced $250 \mathrm{MHz}$ apart instead of the previous $500 \mathrm{MHz}$. Integration times were shortened to about $500 \mathrm{~s}$ per spectrum instead of $1000 \mathrm{~s}$, maintaining a uniform $0.2-0.3 \mathrm{~K}$ rms noise level per resolution element. The resulting single-sideband spectrum was indeed less troubled by false ghosts due to improper sideband separation, despite the generally more intense and crowded spectrum.

\section{c) Line Assignments}

The millimeter-wave spectral line catalogs of F. J. Lovas (1984, private communication) and the Jet Propulsion Laboratory (Poynter and Pickett 1984) again served as the primary sources of reference for our initial line assignments. The difficulties associated with predicting the spectra of the heavier and more complex internal rotors such as $\mathrm{CH}_{3} \mathrm{OH}$ and $\mathrm{HCOOCH}_{3}$ did require some additional laboratory spectroscopy as well, however. Many measurements in this frequency range have been kindly provided by F. C. De Lucia, E. Herbst, and G. M. Plummer of Duke University, and K. V. L. N. Sastry of the University of New Brunswick, particularly for $\mathrm{HCOOCH}_{3}$ (Plummer et al. 1984, 1985) and $\mathrm{CH}_{3} \mathrm{NH}_{2}$ (Sastry et al. 1985). A number of laboratory measurements were also performed on $\mathrm{CH}_{3} \mathrm{OH}$ at JPL to investigate the possibility that high- $J$ methanol transitions were responsible for some of the unidentified lines in our survey (Blake and Pickett 1985).

The combination of supporting laboratory spectroscopy with the existing spectral line catalogs has permitted the identification of nearly all the lines detected in Orion. Only 16 lines remain unidentified in the upper frequency scan, and a total of 33 are left in the entire survey of over 780 detected transitions. We suspect that many of the presently unidentified lines may be due to the excited torsional states or isotopic variants of abundant internal rotors such as $\mathrm{CH}_{3} \mathrm{OCH}_{3}$, $\mathrm{HCOOCH}_{3}$, or $\mathrm{CH}_{3} \mathrm{OH}$, whose rotational spectra are not 
predictable at present (Blake et al. 1984). We would like especially to emphasize that without this supporting laboratory work, hundreds of lines from known interstellar species would have remained unidentified in our surveys.

\section{RESULTS AND DISCUSSION OF INDIVIDUAL SPECIES}

The reduced single-sideband spectrum is presented in Figure 1. A total of 243 resolvable molecular lines, which we ascribe to 23 distinct species, have been detected and labeled in Figure 1. Table 1 presents a list of the detected lines in order of frequency, together with the molecules to which the emission is assigned and the laboratory rest frequencies of the associated rotational transitions. Unidentified lines have been assigned rest frequencies based on a $v_{\text {LSR }}$ of $8 \mathrm{~km} \mathrm{~s}^{-1}$. Further information on the exact line frequencies, transition quantum numbers, and strengths of the astronomical emission is contained below.

\section{a) $\mathrm{SiO}$ and $\mathrm{SO}$}

Silicon monoxide ( $\mathrm{SiO}$ ) has the spectrum of a simple ${ }^{1} \Sigma$ diatomic rotor and is detected through its strong $J=6-5$ line in both the parent ${ }^{28} \mathrm{Si}$ and ${ }^{29} \mathrm{Si}$ isotopes, as Table 2 shows. Both lines are quite broad $\left(\Delta v \geq 30 \mathrm{~km} \mathrm{~s}^{-1}\right)$, indicating that they originate in the plateau source, and seem to show no indication of measurable spike or hot core emission. The $v_{\text {LSR }}$ of the emission peak is near $7 \mathrm{~km} \mathrm{~s}^{-1}$ for both lines. Ratios of the two lines to each other and to $\mathrm{CO}$ indicate that the SiO emission becomes optically thin at velocities greater than about $25 \mathrm{~km} \mathrm{~s}^{-1}$ from the line center and that the silicon monoxide column density is approximately $2 \times 10^{15} \mathrm{~cm}^{-2}$.

Unlike $\mathrm{SiO}$, sulfur monoxide (SO) possesses a nonzero electronic angular momentum which greatly complicates its rotational spectrum. Three lines of ${ }^{32} \mathrm{SO}$ and two transitions of ${ }^{34} \mathrm{SO}$ have been detected in the $247-263 \mathrm{GHz}$ range and are listed in Table 2. As is typical of most sulfur-containing species, all of the lines are dominated by plateau emission $\left(\Delta v \sim 30 \mathrm{~km} \mathrm{~s}^{-1}\right)$, but fits of unconstrained Gaussian components to the line shapes strongly suggest that spike and possibly hot core emission also contribute (Friberg 1984). A more detailed discussion of these results and of the fitting procedure will be presented elsewhere (Blake et al. 1985). They show that SO is greatly enhanced in the plateau source, with at most $2 \%-3 \%$ of the integrated flux due to emission from spike material. The great uniformity of our peak antenna temperatures in the strongest components across the 215-263 $\mathrm{GHz}$ region indicates that emission from $\mathrm{SO}$ is highly saturated. Indeed, ratios of the ${ }^{32} \mathrm{SO} /{ }^{34} \mathrm{SO} 6_{6}-5_{5}$ and $7_{6}-6_{5}$ transitions show that only when $\delta v \geqslant 25-30 \mathrm{~km} \mathrm{~s}^{-1}(\delta v=$ velocity offset from line center) is the emission optically thin. The beam-averaged SO column density is about $3 \times 10^{16} \mathrm{~cm}^{-2}$.

\section{b) $\mathrm{CCH}, \mathrm{NO}$, and NS}

We have detected several components of the $\mathrm{CCH} N=3-2$ transition at $262 \mathrm{GHz}$, previously investigated in detail toward Orion by Ziurys et al. (1982). The rotational spectrum of $\mathrm{CCH}$ is qualitatively similar to that of the $\mathrm{CN}$ radical detected in the lower frequency survey, since both species have ${ }^{2} \Sigma$ ground states. Each rotational transition therefore possesses resolvable fine and hyperfine structure which may be used to estimate the optical depths of individual emission lines. Transition frequencies for the $\Delta J=\Delta N$ components, listed in Table 3, have been taken from Sastry et al. (1982), while those for the $\Delta J$ and $\Delta F=0$ transitions are from Ziurys et al. (1982). The hyperfine splittings of the strongly allowed $J=$ $7 / 2-5 / 2$ and $J=5 / 2-3 / 2$ fine-structure lines at 262005 and $262066 \mathrm{MHz}$ are not resolved, owing to the intrinsic Orion line widths of $\sim 4 \mathrm{~km} \mathrm{~s}^{-1}$; aside from this, however, our results are in agreement with the previous studies of $\mathrm{CCH}$. The strongest lines are marginally optically thick $\left(\tau_{262005} \sim 1.0\right.$ $\pm 0.5)$, corresponding to total column densities of $\sim(3-5) \times$ $10^{15} \mathrm{~cm}^{-2}$ for an assumed rotational temperature of $55 \mathrm{~K}$, derived from the chemically related $\mathrm{CH}_{3} \mathrm{CCH}$ symmetric top.

Also listed in Table 3 is the emission that we have ascribed to the $J=5 / 2-3 / 2$ transition of another free radical, the nitric oxide (NO) molecule. $\mathrm{N}-\mathrm{O}$ bonds are now known to be quite difficult to synthesize in the interstellar medium, and emission from NO is expected to be quite weak. For example, Wootten, Loren, and Bally (1984) tentatively detected one of the $J=3 / 2-1 / 2$ lambda-doubling components near 150.5 $\mathrm{GHz}$ at a level of $\sim 0.2 \mathrm{~K}$ in their study of high-velocity $\mathrm{H}_{2} \mathrm{CO}$ emission toward Orion. The $J=5 / 2-3 / 2$ transitions should be substantially stronger than the ground-state lines, since the NO transitions will undoubtedly be optically thin and fully thermalized because of the low NO dipole moment $\left(\mu_{\mathrm{NO}} \sim 0.16\right.$ debye). Because of the gap near $251 \mathrm{GHz}$, only one of the most strongly allowed lambda-doubling components is presently observed, and it is totally blended with the $28_{3,26}-27_{3,25}$ transition of $\mathrm{C}_{2} \mathrm{H}_{5} \mathrm{CN}$. However, the observed emission is at least a factor of 2 stronger than the expected contribution from $\mathrm{C}_{2} \mathrm{H}_{5} \mathrm{CN}$, and we probably have detected a weaker $\Delta F=0$ hyperfine satellite nearby. Using the known rotational temperature and column density of $\mathrm{C}_{2} \mathrm{H}_{5} \mathrm{CN}$, we have subtracted its expected emission strength from the blended lines to yield the $T_{A}^{*}$ values given in Table 3 . Combining these results with the upper limits derived from the weaker $\Delta F=0$ satellites, we estimate the column density of NO to be $\leqslant 1.5 \times 10^{16} \mathrm{~cm}^{-2}$.

The isoelectronic species NS has not, to our knowledge, been detected in Orion, although a number of investigators have reported its presence in Sgr B2 (Gottlieb et al. 1975; Kuiper et al. 1975; Cummins, Linke, and Thaddeus 1986). The only ground-state $\Pi_{1 / 2}$ lines in our survey fall near 253.5 $\mathrm{GHz}$, where we currently have no spectra. There is an emission feature at the expected position of the excited state $\Pi_{3 / 2}$ lines, but a very high energy $\mathrm{SO}_{2}$ transition $\left(51_{7,45}-50_{8,44}\right)$ is also present at this frequency, and it will not be possible to deconvolve any NS contribution to the emission strength until limits for the ground-state lines are obtained.

\section{c) $\mathrm{OCS}, \mathrm{HCN}, \mathrm{HNC}, \mathrm{HC}_{3} \mathrm{~N}, \mathrm{HCO}^{+}$and $\mathrm{HCS}^{+}$}

The linear OCS molecule has a diatomic rotor-like spectrum and possesses only a single rotational transition in the present search range. The strength of the OCS $J=21-20$ transition, listed in Table 4, is consistent with that of the lower $J$ lines in Paper I, and like these transitions, is a mixture of both the spike and the plateau components, although some hot core 


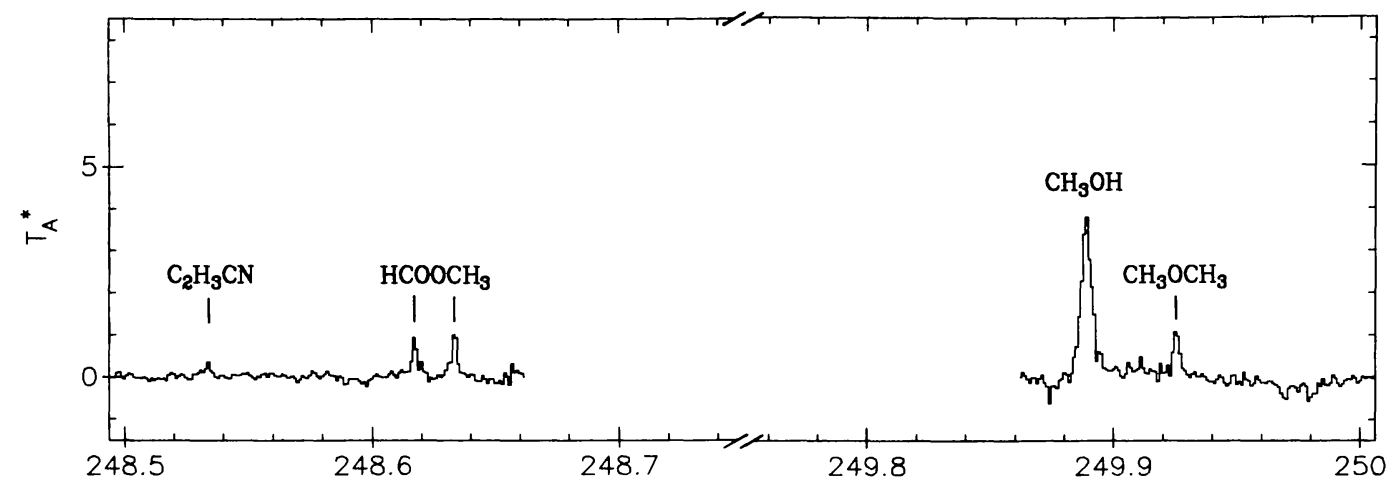

FREQUENCY $(\mathrm{GHz})$
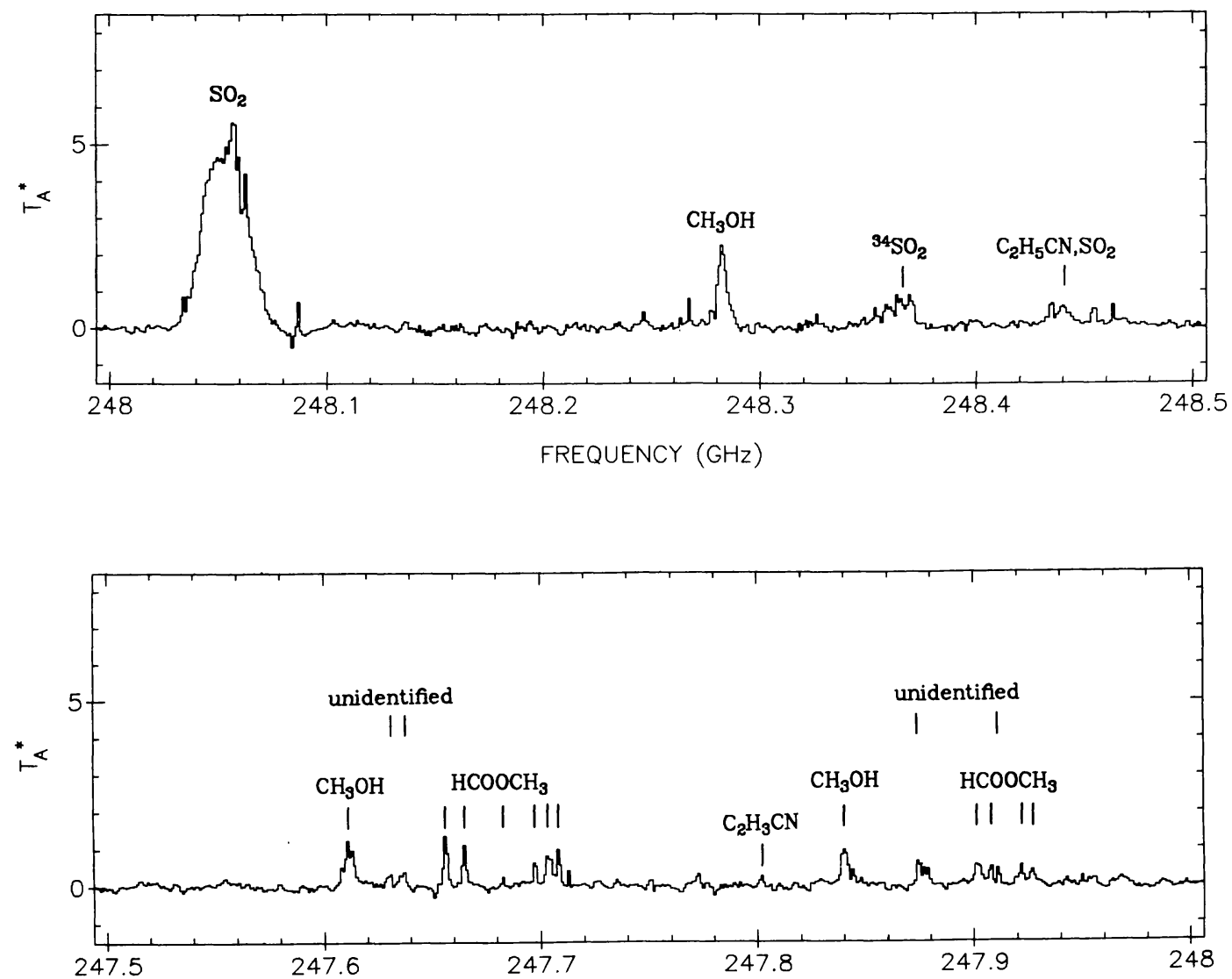

FREQUENCY $(\mathrm{GHz})$

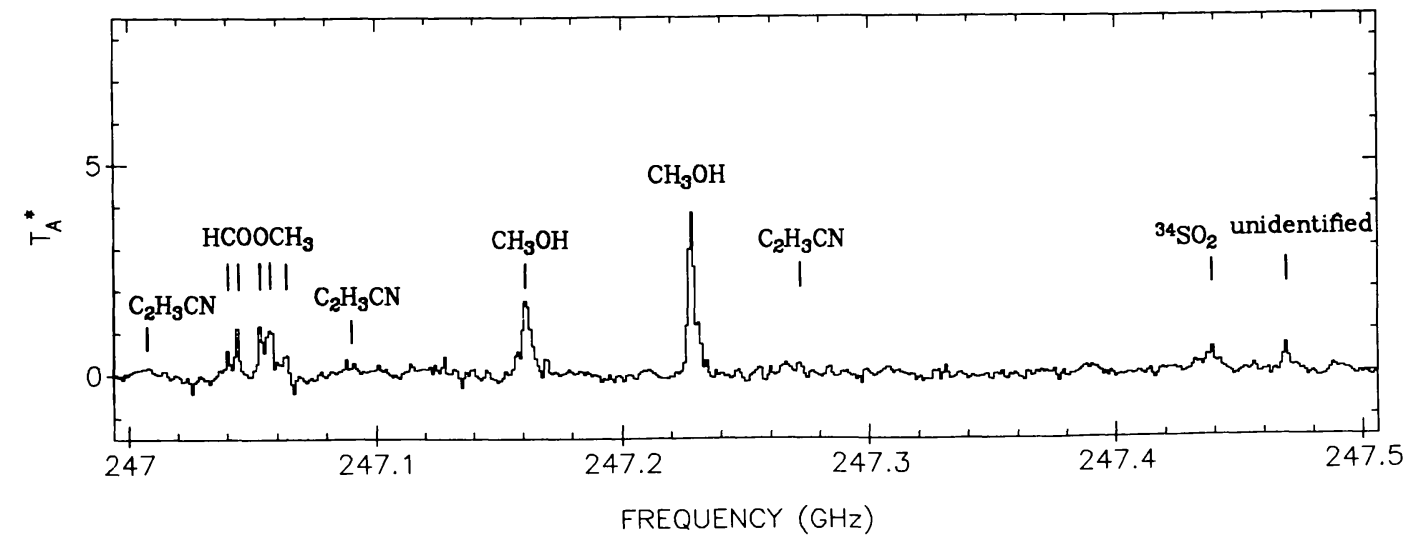

FIG. 1.-Spectrum of Orion A from 247 to $263 \mathrm{GHz}$. The antenna temperature scale has been corrected by the extended source efficiency of 0.85 , while a $v_{\text {LSR }}$ of $8 \mathrm{~km} \mathrm{~s}^{-1}$ has been used to establish the rest frequency scale. Identified lines are individually marked and labeled as to their source. 

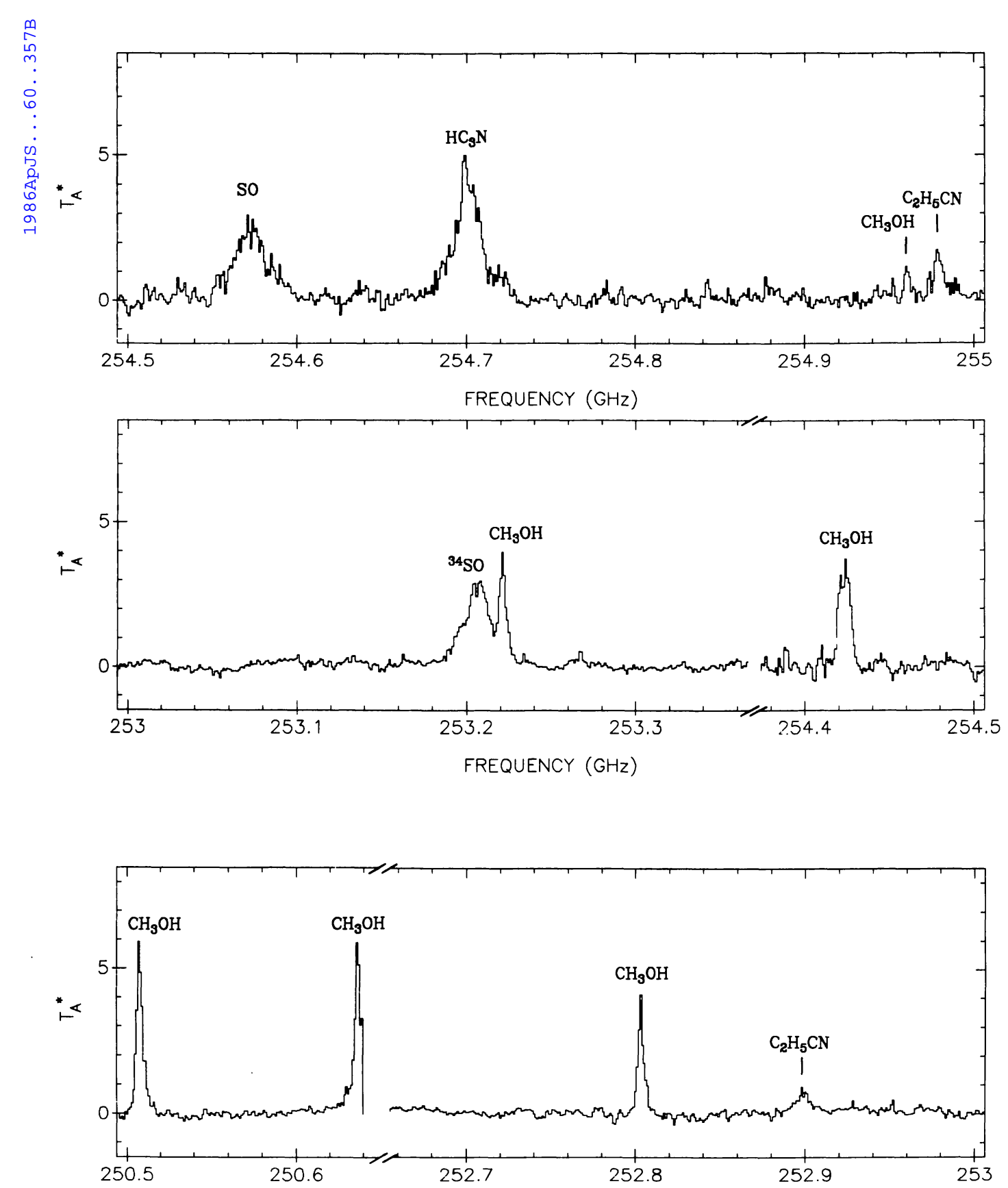

FREQUENCY $(\mathrm{GHz})$

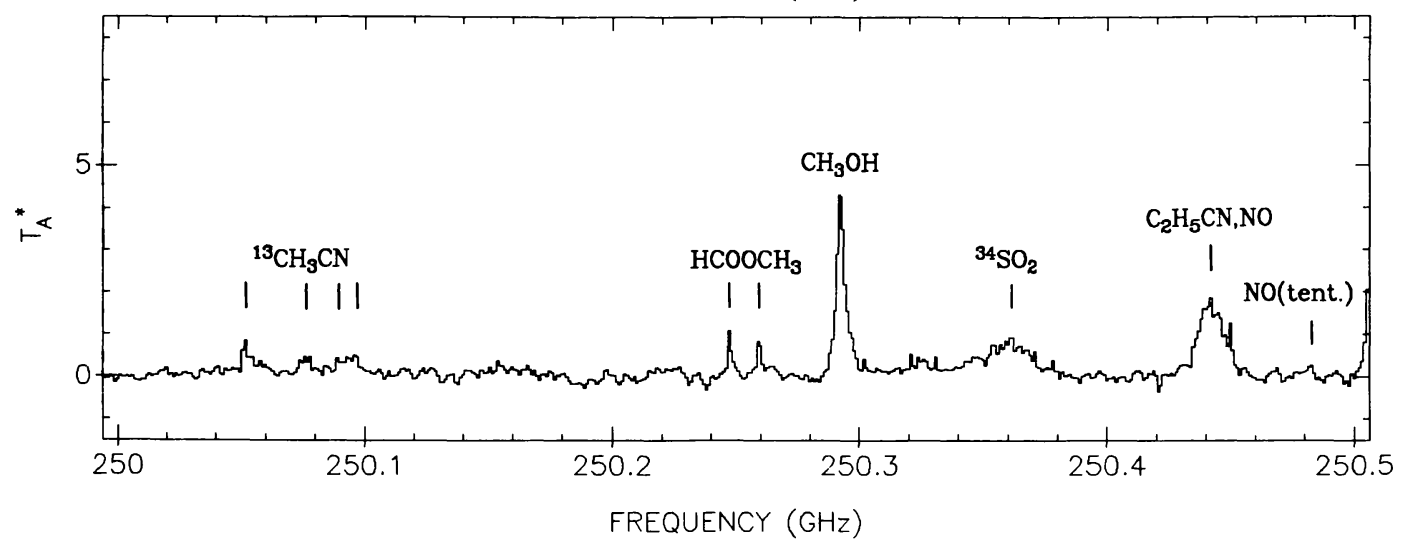

FIG. 1-Continued 

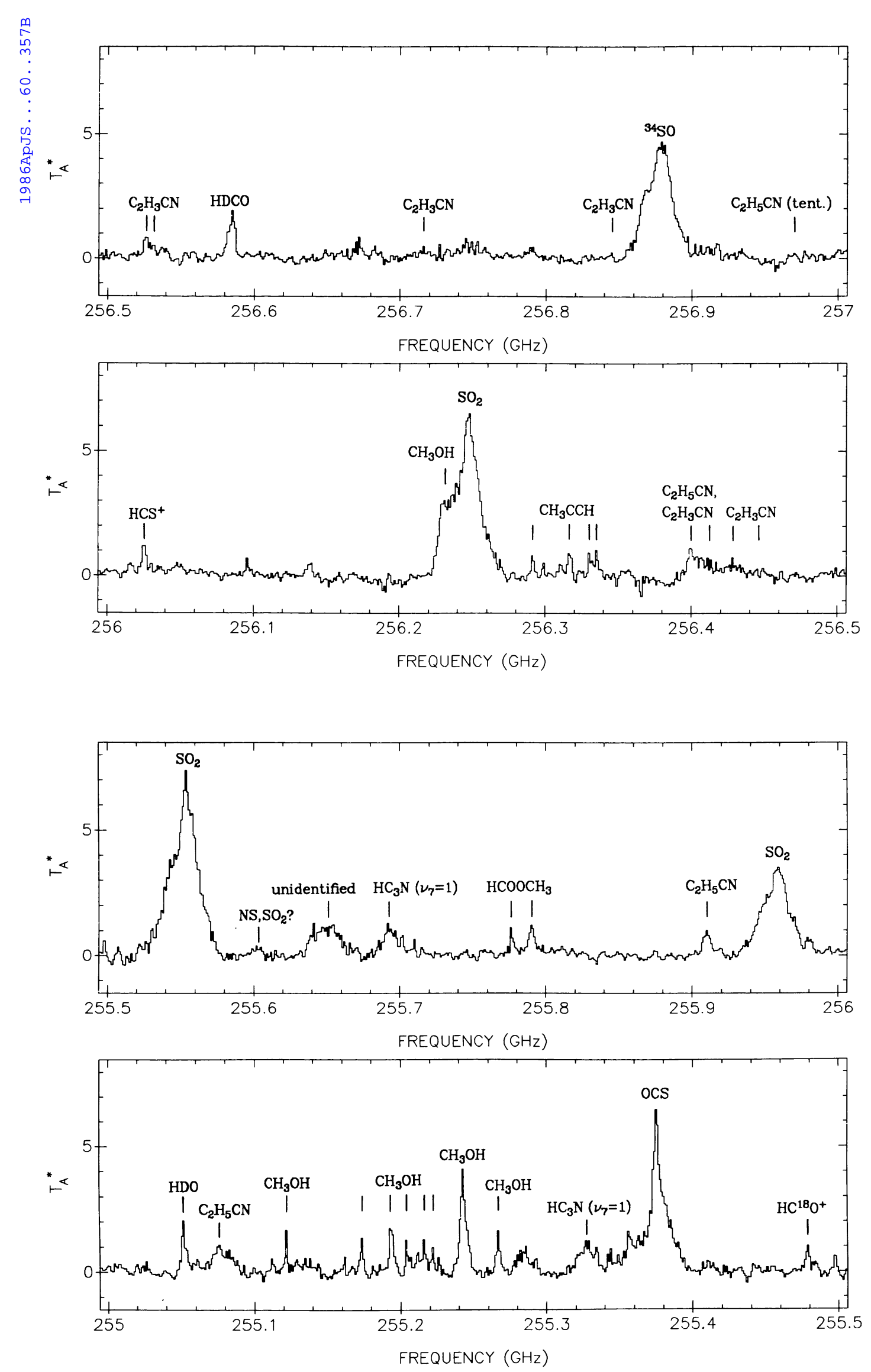

FIG. 1-Continued 


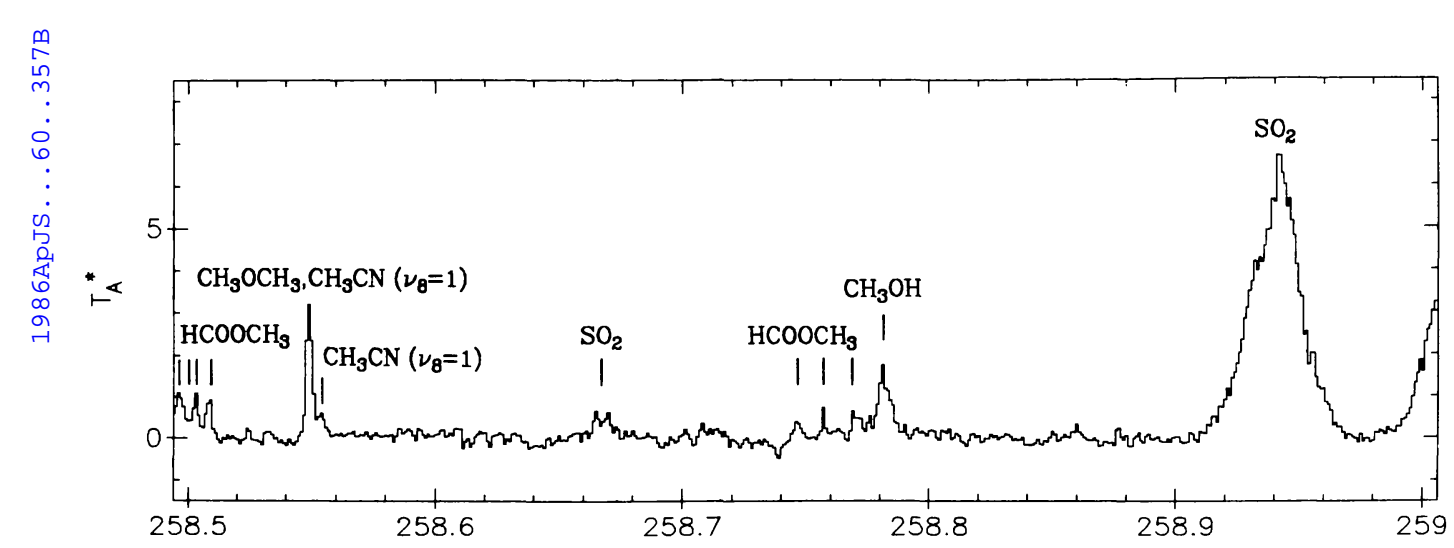

FREQUENCY (GHz)
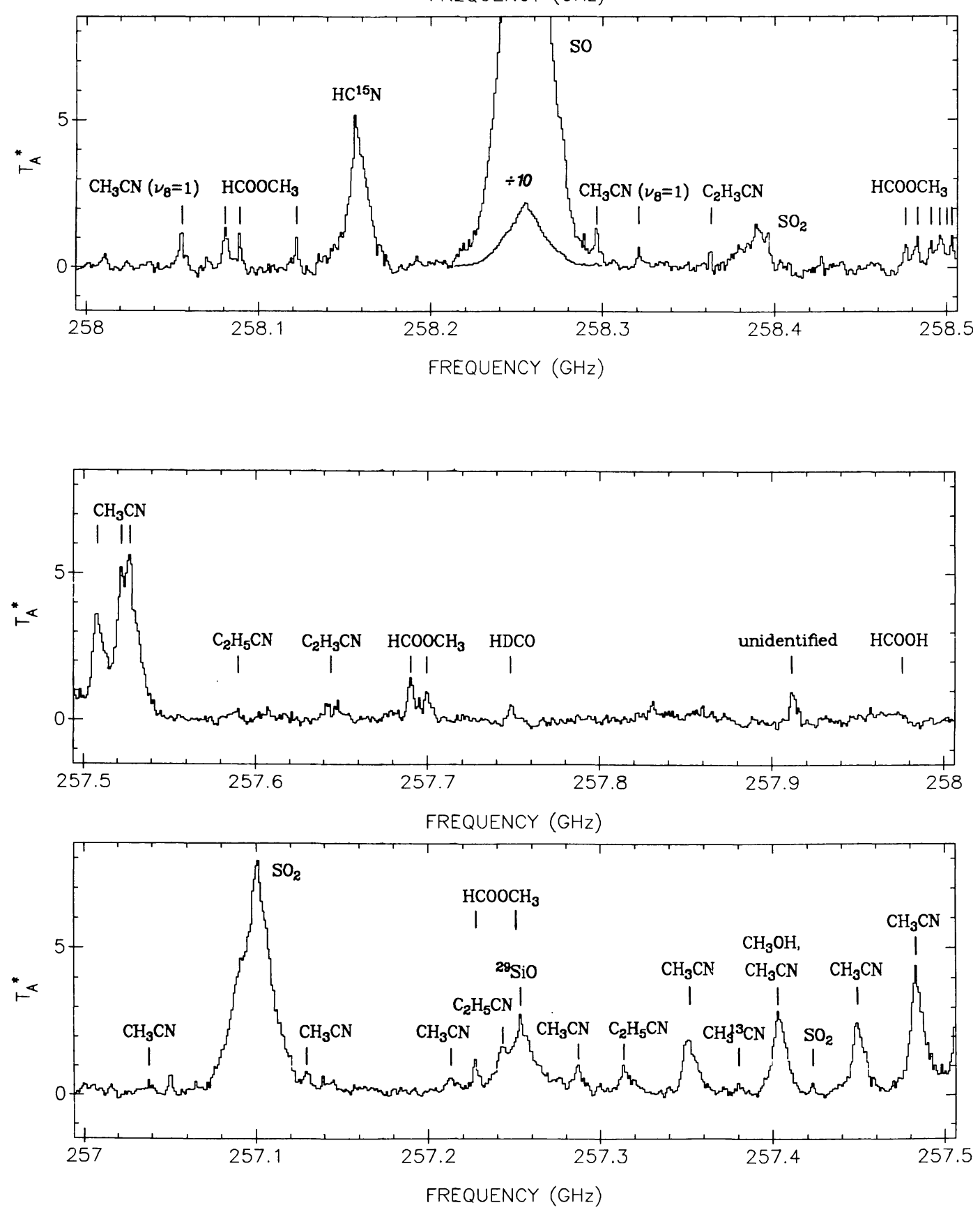

FIG. 1-Continued 

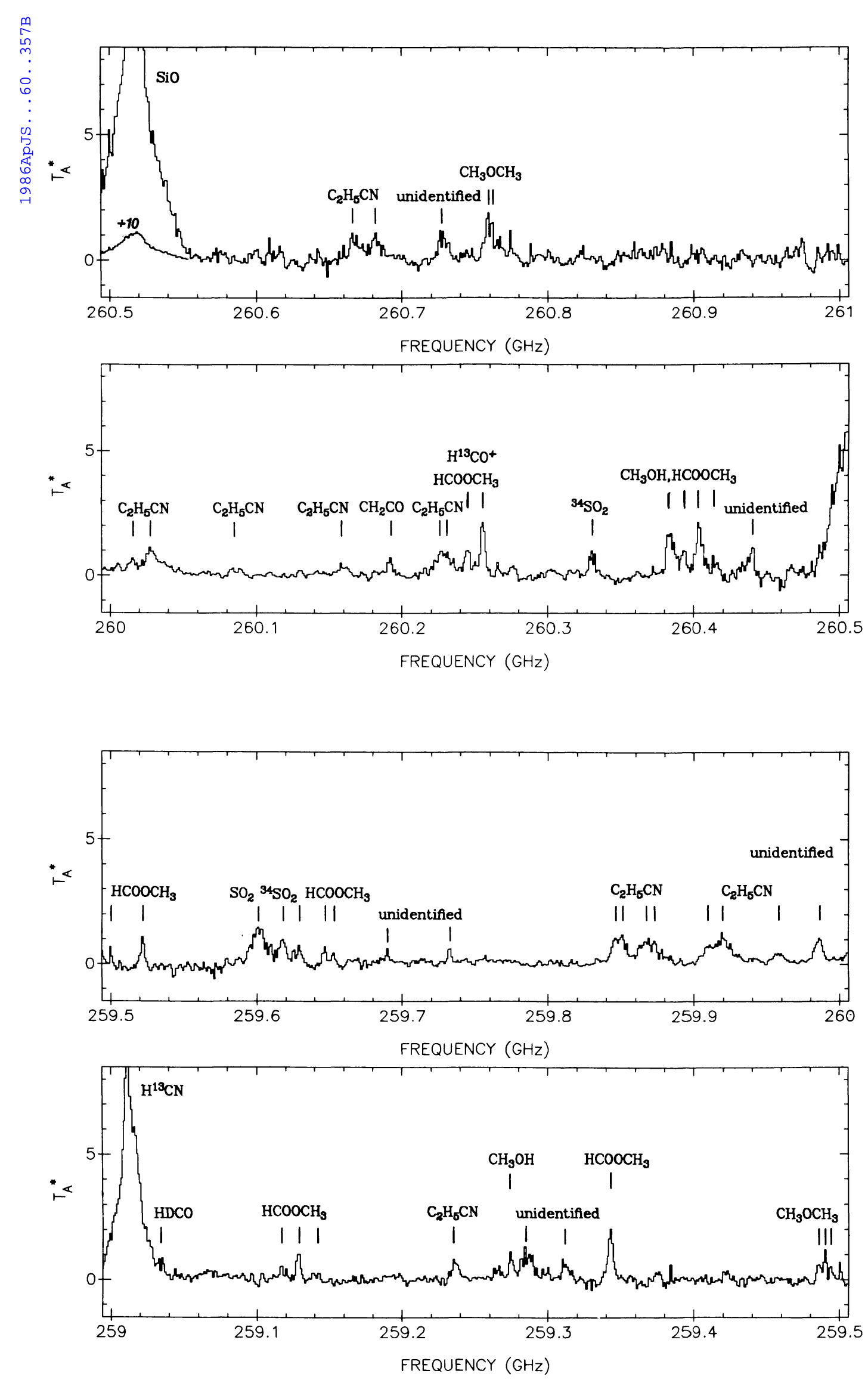

FIG. 1-Continued 

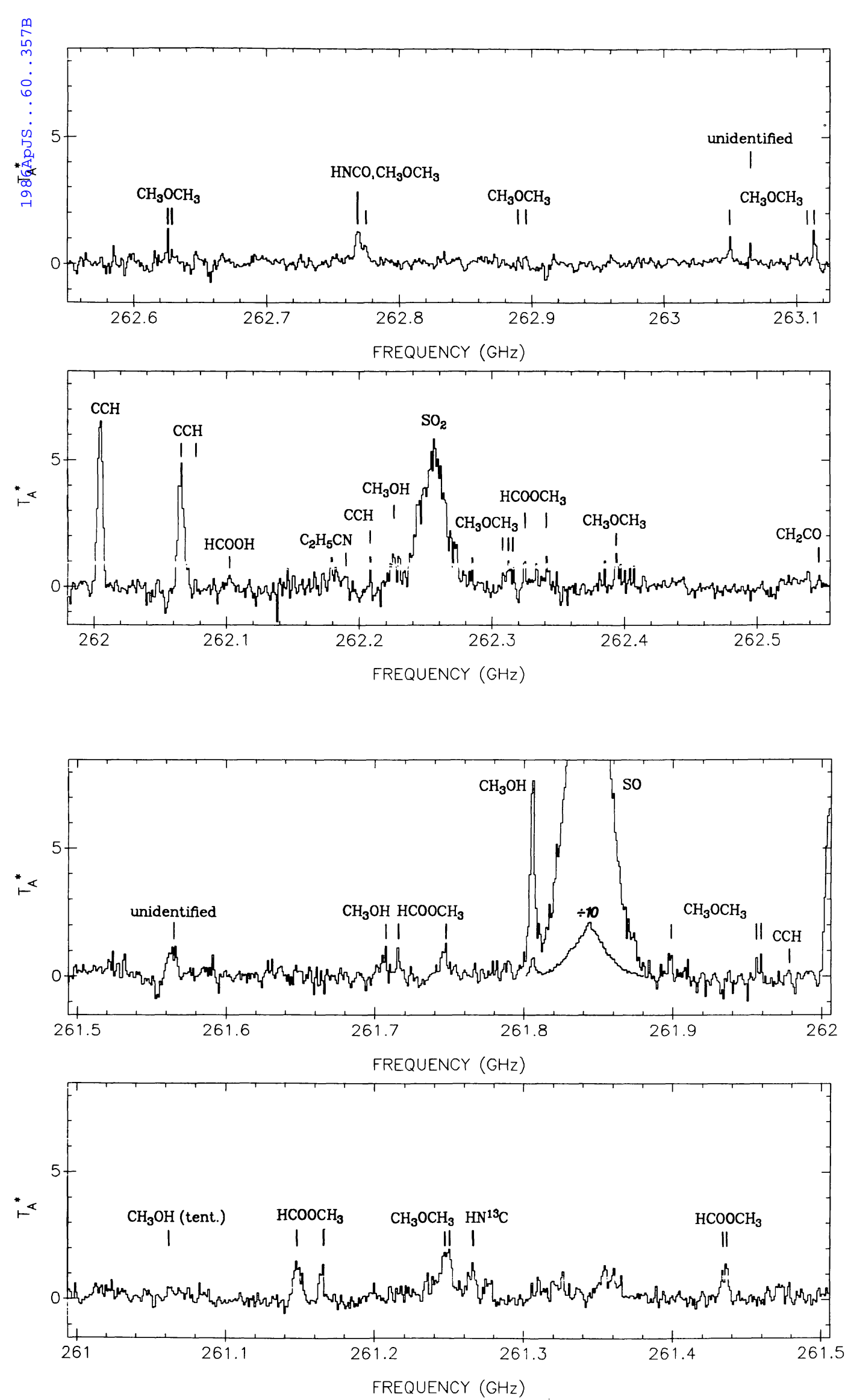

FIG. 1-Continued 


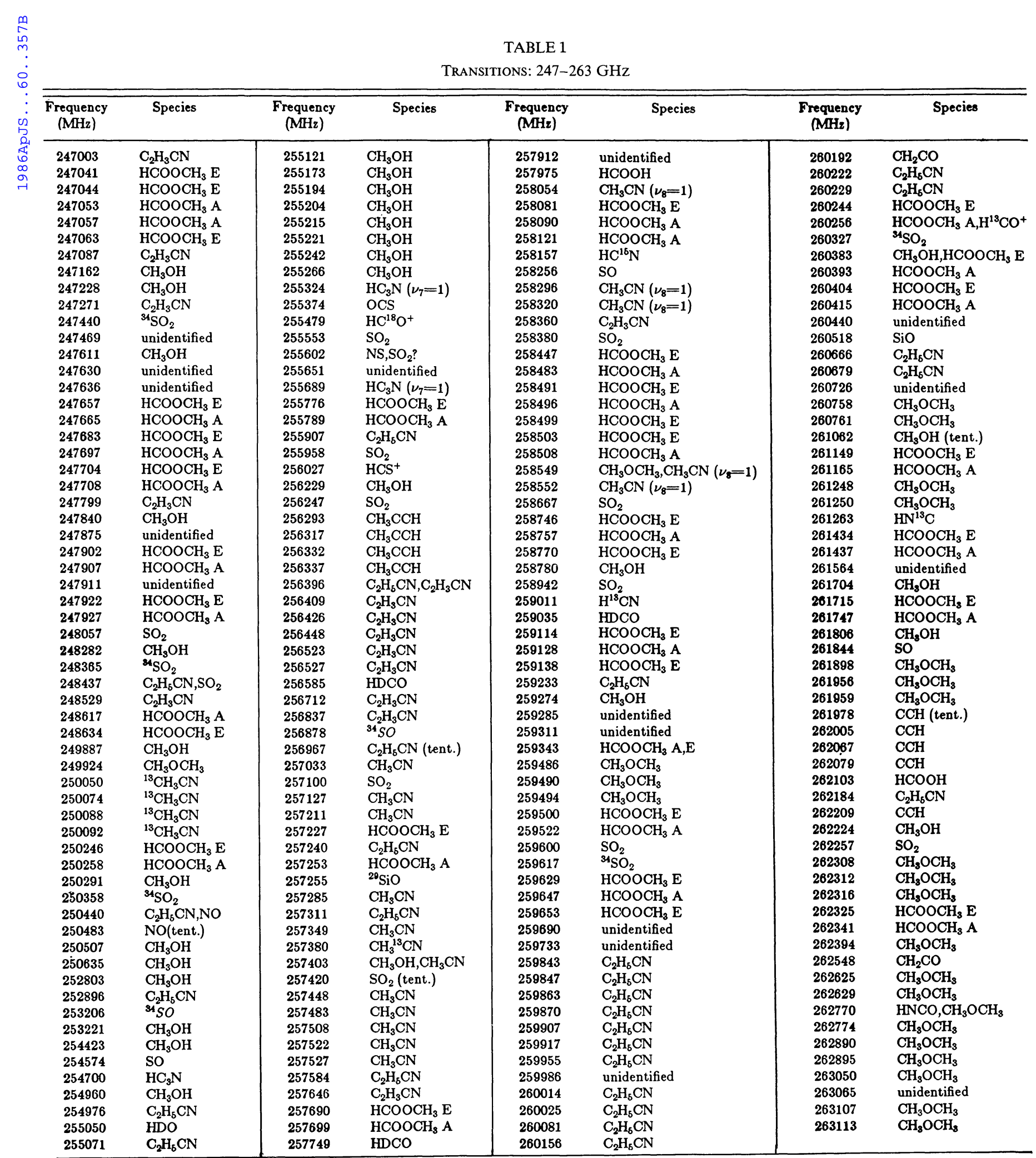


TABLE 2

TRANSITIONS OF SiO AND SO

\begin{tabular}{cccrcc}
\hline \hline & $\begin{array}{c}\nu \\
(\mathrm{MHz})\end{array}$ & $\mathrm{J} / \mathrm{N}_{J}$ & $\begin{array}{r}\mathrm{T}_{\mathbf{2}}^{*} \\
(\mathrm{~K})\end{array}$ & $\begin{array}{c}\int \mathrm{T}_{\mathbf{2}}^{*} \mathrm{dv} \\
\left(\mathrm{K} \mathrm{km} \mathrm{s}^{-1}\right)\end{array}$ & notes \\
\hline $\mathrm{SiO} \ldots \ldots .$. & 260518.0 & $6-5$ & 11.3 & 374. & \\
${ }^{20} \mathrm{SiO} \ldots . .$. & 257255.0 & $6-5$ & 1.6 & 41.2 & a \\
& & & & & \\
$\mathrm{SO} \ldots \ldots .$. & 254573.5 & $8_{9}-8_{8}$ & 3.0 & $\mathbf{7 4 . 3}$ & \\
& 258255.8 & $6_{6}-5_{5}$ & 21.8 & 662. & \\
& 261843.7 & $7_{6}-6_{5}$ & 21.8 & 647. & \\
${ }^{34} \mathrm{SO} \ldots . . .$. & 253206.6 & $6_{6}-5_{5}$ & 3.0 & 72.5 & \\
& 256877.8 & $7_{6}-6_{5}$ & 4.7 & 115. & \\
\hline
\end{tabular}

${ }^{\text {a }}$ Blend with $\mathrm{C}_{2} \mathrm{H}_{5} \mathrm{CN} 257240$ and $\mathrm{HCOOCH}_{3} 257253$.

emission may also be present. No isotopic lines have been detected.

The $J=3-2$ transitions of $\mathrm{HCN}$ and $\mathrm{HNC}$ have been detected in the ${ }^{13} \mathrm{C}$ and ${ }^{15} \mathrm{~N}$ isotopic variants of $\mathrm{HCN}$ and only in the ${ }^{13} \mathrm{C}$ substituted isotope for HNC. The parent isotopic transitions for both species lie above the frequency range searched. As Figure 1 and Table 4 show, emission from the $\mathrm{HC}^{15} \mathrm{~N}$ and $\mathrm{H}^{13} \mathrm{CN}$ lines is quite strong and is clearly composed of spike, hot core, and plateau components. Fits of Gaussian profiles to the data yield average $v_{\text {LSR }}$ and $\Delta v$ parameters of 9.0 and $3.5 \mathrm{~km} \mathrm{~s}^{-1}$ for the spike material, 5.8 and $12.3 \mathrm{~km} \mathrm{~s}^{-1}$ for the hot core, and 8.6 and $27.0 \mathrm{~km} \mathrm{~s}^{-1}$ for the plateau source, and reveal that the $\mathrm{HCN}$ abundance is enhanced in both the hot core and the plateau sources relative to the ambient molecular cloud. HNC shows mostly spike emission, however, with the possibility of some hot core emission at a lower level.

Like $\mathrm{HCN}$, the ground-state cyanoacetylene $\left(\mathrm{HC}_{3} \mathrm{~N}\right)$ line shape is seen to consist of emission from all three Orion kinematic components. Emission from the $J=28-27 \nu_{7}=1$ vibrationally excited lines is also clearly evident in Figure 1 , and shows only the hot core line shape $\left(v_{\mathrm{LSR}} \sim 4.6 \mathrm{~km} \mathrm{~s}^{-1}\right.$,
TABLE 4

Transitions of OCS, $\mathrm{HCN}, \mathrm{HNC}, \mathrm{HC}_{3} \mathrm{~N}, \mathrm{HCO}^{+}$, AND $\mathrm{HCS}^{+}$

\begin{tabular}{|c|c|c|c|c|c|}
\hline & $\begin{array}{c}\nu \\
(\mathrm{MHz})\end{array}$ & $\mathbf{J}$ & $\begin{array}{l}\mathrm{T}_{2}^{*} \\
(\mathrm{~K})\end{array}$ & $\underset{\left(\mathrm{K} \mathrm{km} \mathrm{s}{ }^{-1}\right)}{\int \mathrm{T}_{\mathrm{z}}^{*} \mathrm{dv}}$ & notes \\
\hline OCS....................... & 255374.5 & $21-20$ & 6.5 & 88.8 & \\
\hline $\mathrm{HC}^{16} \mathrm{~N} \ldots \ldots \ldots \ldots \ldots$ & 258157.3 & $3-2$ & 5.2 & 75.8 & \\
\hline $\mathrm{H}^{13} \mathrm{CN} \ldots \ldots \ldots \ldots \ldots$ & 259011.7 & $3-2$ & 9.0 & 157. & \\
\hline $\mathrm{HN}^{18} \mathrm{C} \ldots \ldots \ldots \ldots$ & 261263.4 & $3-2$ & 0.9 & 4.0 & \\
\hline $\mathrm{HC}_{3} \mathrm{~N} \ldots \ldots \ldots \ldots$ & 254699.6 & $28-27$ & 5.0 & 106. & \\
\hline \multirow[t]{2}{*}{$\mathrm{HC}_{3} \mathrm{~N}\left(\nu_{7}=1\right) \ldots$} & 255324.3 & $28-27 \mathrm{le}$ & 1.0 & 17.7 & \\
\hline & 255689.1 & $28-27$ if & 1.1 & 15.6 & \\
\hline $\mathrm{HC}^{18} \mathrm{O}^{+} \ldots \ldots \ldots \ldots$ & 255479.4 & $3-2$ & 1.0 & 3.4 & \\
\hline $\mathrm{H}^{13} \mathrm{CO}^{+} \ldots \ldots \ldots \ldots$ & 260255.5 & $3-2$ & $z 1.0$ & $z^{4.1}$ & a \\
\hline $\mathrm{HCS}^{+}$. & 256027.4 & $6-5$ & 1.2 & 5.2 & \\
\hline
\end{tabular}

${ }^{a}$ Blend with $\mathrm{HCOOCH}_{3} 260256$.

$\Delta v \sim 12.1 \mathrm{~km} \mathrm{~s}^{-1}$ ) because of the excitation requirements of these transitions $\left(E_{\text {lower }} \sim 250 \mathrm{~cm}^{-1}\right)$. Average parameters for Gaussian components fitted to the ground-state $\mathrm{HC}_{3} \mathrm{~N}$ lines are quite similar to the $\mathrm{HCN}$ values, and indicate that cyanoacetylene is most abundant in the hot core and plateau sources. No isotopic lines have been detected either in Paper I or in the $247-263 \mathrm{GHz}$ interval.

The $\mathrm{HCO}^{+}$and $\mathrm{HCS}^{+}$ionized variations of the familiar HCX linear interstellar molecules have also been detected here and are listed in Table 4. As with the neutral HCN and HNC species discussed above, the parent isotopic $\mathrm{HCO}^{+}$transition lies above our current frequency range, but is detected through the $\mathrm{H}^{13} \mathrm{CO}^{+}$and $\mathrm{HC}^{18} \mathrm{O}^{+}$isotopic forms. The $\mathrm{HCS}^{+}$and isotopic $\mathrm{HCO}^{+}$emission arise purely from the extended, quiescent molecular cloud material $\left(v_{\mathrm{LSR}} \sim 8 \mathrm{~km} \mathrm{~s}^{-1}, \Delta v \sim 3.8\right.$ $\mathrm{km} \mathrm{s}^{-1}$ ), as expected. Emission from the higher density and temperature hot core and plateau components is not favored

TABLE 3

TRANSITIONS OF CCH, NO, AND NS

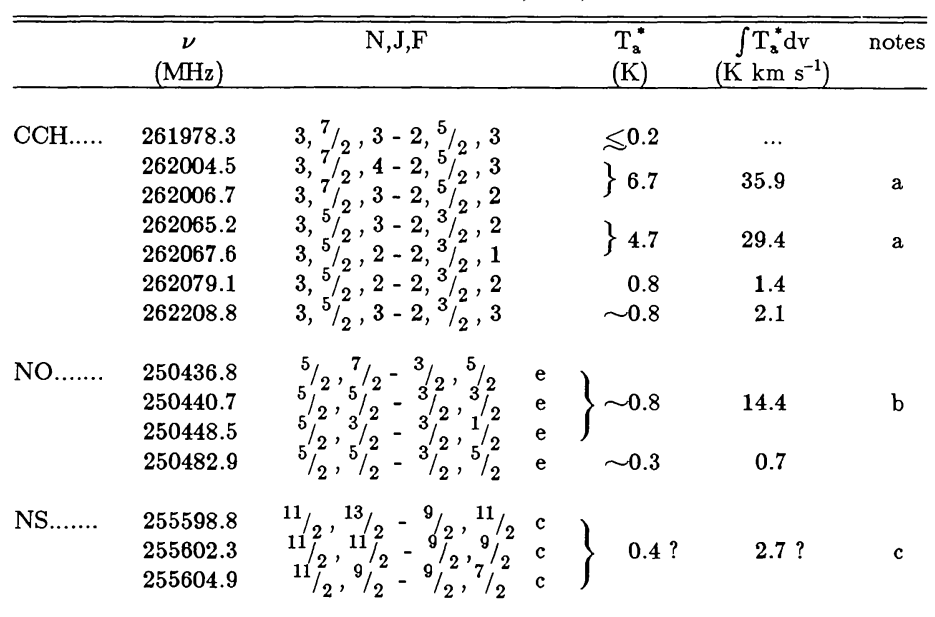

\footnotetext{
${ }^{a}$ Hyperfine components not resolved.

${ }^{b} \mathrm{NO}$ lines blended with $\mathrm{C}_{2} \mathrm{H}_{5} \mathrm{CN} 250440$, total integrated flux from all three components listed.

${ }^{\mathrm{c}}$ Due to $\mathrm{SO}_{2} 255595 ?$
} 
because of the greatly reduced fractional ionization in these sources. The $\mathrm{H}^{13} \mathrm{CO}^{+}$line is strongly blended with the $21_{3,18}-20_{3,17}$ A-type transition of $\mathrm{HCOOCH}_{3}$, whose contribution is subtracted from the overall emission using the nearby E-type $\mathrm{HCOOCH}_{3}$ component to give the $\mathrm{H}^{13} \mathrm{CO}^{+} T_{A}^{*}$ listed in Table 4. Column densities of $\mathrm{HCO}^{+}$and $\mathrm{HCS}^{+}$are estimated to be about $1.5 \times 10^{15}$ and $1.6 \times 10^{13} \mathrm{~cm}^{-1}$, respectively. A lower bound to the quiescent cloud fractional ionization of $f\left(e^{-}\right)>5 \times 10^{-9}$ is derived from the $\mathrm{HC}^{18} \mathrm{O}^{+}$line.

\section{d) $\mathrm{CH}_{3} \mathrm{CN}$ and $\mathrm{CH}_{3} \mathrm{CCH}$}

The $J=14-13$ ground state and first vibrationally excited $\left(\nu_{8}=1\right)$ bands listed in Table 5 bring the total number of methyl cyanide $\left(\mathrm{CH}_{3} \mathrm{CN}\right)$ lines detected in the complete survey to over 65. As discussed in Paper I and by Loren and Mundy (1984), low- $J$ lines in the ground-state bands are mixtures of both spike and hot core components, while the high- $J$ ground-state lines and all the vibrationally excited transitions are due exclusively to the hot core. Average Gaussian components for the two sources have radial velocities and line widths of 8.4 and $4.0 \mathrm{~km} \mathrm{~s}^{-1}$ and 5.6 and $10.3 \mathrm{~km} \mathrm{~s}^{-1}$, respectively. Excitation temperatures and column densities of the two $\mathrm{CH}_{3} \mathrm{CN}$ sources are unchanged from the the values of $100 \mathrm{~K}$ and $2 \times 10^{14} \mathrm{~cm}^{-2}$ and $285 \mathrm{~K}$ and $2 \times 10^{15} \mathrm{~cm}^{-2}$ estimated in Paper I from a similar Gaussian decomposition of the ground-state line shapes. Many of the strongest lines in the $\nu_{8}=1$ band are buried in the intense $6_{6}-5_{5}$ transition of SO, but the unaffected lines have an average width of $9.8 \mathrm{~km} \mathrm{~s}^{-1}$ and a $v_{\text {LSR }}$ of $6.4 \mathrm{~km} \mathrm{~s}^{-1}$.

Isotopically substituted methyl cyanide has once again been detected in the ${ }^{13} \mathrm{CH}_{3} \mathrm{CN}$ and $\mathrm{CH}_{3}{ }^{13} \mathrm{CN}$ variants, which are also listed in Table 5. The average $v_{\text {LSR }}$ of $5.3 \mathrm{~km} \mathrm{~s}^{-1}$ and $\Delta v$ of $7.2 \mathrm{~km} \mathrm{~s}^{-1}$ are suggestive of hot core emission. For an assumed rotational temperature of $\leqslant 285 \mathrm{~K}$ the derived column density of $\leqslant 1 \times 10^{14} \mathrm{~cm}^{-2}$ corresponds to a ${ }^{13} \mathrm{C} /{ }^{12} \mathrm{C}$ ratio of $\gtrsim 20$, consistent with the low values derived from $\mathrm{HCN}, \mathrm{NHC}$, and $\mathrm{CH}_{3} \mathrm{OH}$, and with those from the Onsala survey of Orion (Johansson et al. 1984).

The $J=15-14$ band of methyl acetylene $\left(\mathrm{CH}_{3} \mathrm{CCH}\right)$, another symmetric top whose mass and structure are very similar to $\mathrm{CH}_{3} \mathrm{CN}$, lies near $256 \mathrm{GHz}$ and is characterized by purely spike emission with a $v_{\mathrm{LSR}}$ and line width of 9.3 and $3.8 \mathrm{~km} \mathrm{~s}^{-1}$, respectively, as Table 5 shows. Ratios of the $K$-ladder components support the low excitation temperature of $T_{\mathrm{ROT}} \sim 55 \mathrm{~K}$ derived in Paper I, which has also been used for other molecules showing extended emission such as $\mathrm{CN}$ and $\mathrm{CCH}$. No isotopic lines of methyl acetylene have been detected.

\section{e) $\mathrm{CH}_{3} \mathrm{OH}$}

Methanol $\left(\mathrm{CH}_{3} \mathrm{OH}\right)$ emission in the $247-263 \mathrm{GHz}$ region is dominated by the $K=3^{+}-2^{-}$and $3^{-}-2^{+}$A-symmetry $Q$ branches whose band heads lie near $252 \mathrm{GHz}$. Weaker $P_{-}$and $R$-branch transitions lie scattered irregularly throughout the scan. The $Q$-branch lines are quite strong and occur in a monotonically spaced series which may be simply predicted algebraically. Lines up to $J=22$ have been detected in our survey by extrapolating the transitions measured in the laboratory to higher $J$-values. It is therefore highly likely that
TABLE 5

Transitions of $\mathrm{CH}_{3} \mathrm{CN}$ AND $\mathrm{CH}_{3} \mathrm{CCH}$

\begin{tabular}{|c|c|c|c|c|c|c|}
\hline & $\begin{array}{c}\nu \\
(\mathrm{MHz})\end{array}$ & $\mathbf{J}_{K}$ & & $\begin{array}{l}T_{2}^{*} \\
(\mathrm{~K})\end{array}$ & $\underset{\left(K \mathrm{~km} \mathrm{~s}^{-1}\right)}{\int \mathrm{T}_{\mathrm{a}}^{*} \mathrm{~d} \mathbf{v}}$ & notes \\
\hline \multirow[t]{11}{*}{$\mathrm{CH}_{3} \mathrm{CN} \ldots \ldots \ldots \ldots \ldots \ldots$} & 257033.6 & $14_{10}-13_{10}$ & & 0.3 & 3.6 & \\
\hline & 257127.1 & $14_{9}-13_{0}$ & & 0.6 & 3.5 & \\
\hline & 257211.0 & $14_{8}-13_{8}$ & & 0.6 & 5.0 & \\
\hline & 257285.0 & $14_{7}-13_{7}$ & & 1.0 & 9.6 & \\
\hline & 257349.2 & $14_{\theta}-13_{\theta}$ & & 1.8 & 22.6 & \\
\hline & 257403.6 & $14_{5}-13_{5}$ & & 2.8 & 33.3 & a \\
\hline & 257448.1 & $14_{4}-13_{4}$ & & 2.5 & 27.3 & \\
\hline & 257482.8 & $14_{3}-13_{3}$ & & 4.3 & 54.1 & \\
\hline & 257507.6 & $14_{2}-13_{2}$ & & 3.6 & 28.4 & \\
\hline & 257522.4 & $14_{1}-13_{1}$ & & 5.1 & 40.2 & \\
\hline & 257527.4 & $14_{0}-13_{0}$ & & 5.6 & 44.2 & \\
\hline \multirow[t]{12}{*}{$\mathrm{CH}_{3} \mathrm{CN}\left(\nu_{8}=1\right) \ldots$} & 258054.1 & $14_{1}-13_{1}$ & (1) & 1.1 & 5.0 & \\
\hline & 258170.4 & $14_{4}-13_{4}$ & $(-1)$ & $\ldots$ & $\ldots$ & b \\
\hline & 258187.0 & $14_{\theta}-13_{6}$ & (1) & 0.3 & 1.8 & \\
\hline & 258215.0 & $14_{3}-13_{3}$ & $(-1)$ & & & \\
\hline & 258232.1 & $14_{5}-13_{5}$ & (1) & & & \\
\hline & 258248.9 & $14_{2}-13_{2}$ & $(-1)$ & & & c \\
\hline & 258267.9 & $14_{4}-13_{4}$ & (1) & $\cdots$ & $\cdots$ & c \\
\hline & 258271.1 & $14_{1}-13_{1}$ & $(-1)$ & & & \\
\hline & 258276.2 & $14_{0}-13_{0}$ & (1) & & & \\
\hline & 258296.6 & $14_{3}-13_{3}$ & (1) & 1.1 & 6.6 & \\
\hline & 258320.4 & $14_{2}-13_{2}$ & (1) & 0.7 & 3.3 & \\
\hline & 258552.4 & $14_{1}-13_{1}$ & (1) & 0.6 & 3.5 & \\
\hline $\mathrm{CH}_{3}{ }^{13} \mathrm{CN} \ldots \ldots \ldots \ldots$ & 257380.2 & $14_{2}-13_{2}$ & & 0.3 & 1.9 & \\
\hline \multirow{4}{*}{${ }^{13} \mathrm{CH}_{3} \mathrm{CN} \ldots \ldots \ldots \ldots$} & 250050.2 & $14_{3}-13_{3}$ & & 0.6 & 3.8 & d \\
\hline & 250073.7 & $14_{2}-13_{2}$ & & 0.5 & 3.7 & \\
\hline & 250087.8 & $14_{1}-13_{1}$ & & 0.3 & 2.8 & \\
\hline & 250092.5 & $14_{0}-13_{0}$ & & 0.4 & 3.6 & \\
\hline \multirow[t]{4}{*}{$\mathrm{CH}_{3} \mathrm{CCH} \ldots \ldots \ldots \ldots$} & 256292.6 & $15_{3}-14_{3}$ & & 0.8 & 2.1 & \\
\hline & 256317.1 & $15_{2}-14_{2}$ & & 0.9 & 3.9 & d \\
\hline & 256331.8 & $15_{1}-14_{1}$ & & 0.8 & 2.9 & \\
\hline & 256336.6 & $15_{0}-14_{0}$ & & 0.9 & 3.3 & \\
\hline
\end{tabular}

${ }^{\text {a }}$ Blend with $\mathrm{CH}_{3} \mathrm{OH} 257402$.

${ }^{b}$ Lost to $\mathrm{HC}^{15} \mathrm{~N}$.

${ }^{c}$ Lost to SO 258256 .

${ }^{\mathrm{d}}$ Too strong, blend?

$\mathrm{CH}_{3} \mathrm{OH}$ emission from levels as high as $J=25$ or 30 will be readily detectable in Orion, but the large perturbations in the rotational spectrum induced by the intermediate torsional barrier height make predictions for $J \geq 10$ highly uncertain (Herbst et al. 1984).

As a step toward identifying the higher $J$ spectrum of $\mathrm{CH}_{3} \mathrm{OH}$ in the laboratory, we have used the initially unidentified lines in our survey to search for unassigned methanol transitions in the $210-265 \mathrm{GHz}$ range. By observing the laboratory spectrum of methanol vapor in the vicinity of the unidentified lines, we had also hoped to verify our suspicion that a number of them were in fact due to $\mathrm{CH}_{3} \mathrm{OH}$. And indeed, as a result of these laboratory experiments (Blake and Pickett 1985), 15 of some 40 initially unidentified lines have now been definitively assigned to methanol. Rest frequencies of the newly measured $\mathrm{CH}_{3} \mathrm{OH}$ lines are listed in Table 6 along with their associated astronomical emission. Assignment of the transition quantum numbers and excitation energies is not possible at the present time, but must await further spectroscopic and theoretical work.

Although an extended methanol source clearly exists in Orion, its emission arises predominantly from a compact $\left(\vartheta_{\text {meth }} \leq 30^{\prime \prime}\right)$ region of warm material at the edge of the 8 
TABLE 6

Transitions of $\mathrm{CH}_{3} \mathrm{OH}$

\begin{tabular}{|c|c|c|c|c|c|}
\hline & $\begin{array}{c}\nu \\
(\mathrm{MHz}) \\
\end{array}$ & $\mathrm{J}_{K}$ & $\begin{array}{l}\mathrm{T}_{\mathrm{a}}^{*} \\
(\mathrm{~K})\end{array}$ & $\underset{\left(\mathrm{K} \mathrm{km} \mathrm{s}^{-1}\right)}{\mathrm{T}_{\mathrm{a}}^{*} \mathrm{dv}}$ & notes \\
\hline \multirow[t]{31}{*}{$\mathrm{CH}_{3} \mathrm{OH} \ldots$} & 247162.1 & unassigned & 1.6 & 10.2 & \\
\hline & 247228.7 & $4_{2} A+-5_{1} A+$ & 3.9 & 18.2 & \\
\hline & 247611.0 & $18_{3 A-}-18_{2 A+}$ & 1.1 & 7.5 & \\
\hline & 247840.2 & unassigned & 1.0 & 4.9 & \\
\hline & 248242.5 & $17_{3 A_{-}-} 17_{2 A+}$ & 2.2 & 13.4 & \\
\hline & 249887.5 & $14_{3 A-}-14_{2 A+}$ & 3.6 & 23.0 & \\
\hline & 250291.2 & $13_{3 A-}-13_{2 A+}$ & 4.2 & 25.8 & \\
\hline & 250507.0 & $11_{0 A+}-10_{1 A+}$ & 5.8 & 32.7 & \\
\hline & 250635.2 & $12_{3 A-}-12_{2 A+}$ & 5.9 & 37.6 & \\
\hline & 252803.4 & $12_{3 A+}-12_{2} A-$ & 4.1 & 20.2 & \\
\hline & 253221.4 & $13_{3 A+}-13_{2 A-}$ & 3.1 & 17.6 & a \\
\hline & 254423.6 & $\begin{array}{c}15_{3 A+}-15_{2} A- \\
11_{5 E}-12_{4 E}\end{array}$ & 33.0 & 34.6 & b \\
\hline & 254959.5 & unassigned & 1.2 & 5.5 & \\
\hline & 255121.0 & unassigned & 1.7 & 3.2 & \\
\hline & 255173.0 & unassigned & 1.2 & 4.0 & \\
\hline & 255192.5 & unassigned & 1.8 & 8.1 & c \\
\hline & 255193.5 & unassigned & & & \\
\hline & 255203.8 & unassigned & 1.3 & 2.8 & \\
\hline & 255214.9 & unassigned & 1.1 & 4.3 & \\
\hline & 255220.9 & unassigned & 0.9 & 2.7 & \\
\hline & 255242.0 & $16_{3 A+}-16_{2 A-}$ & 3.8 & 23.9 & \\
\hline & 255265.7 & unassigned & 1.4 & 5.2 & \\
\hline & 256228.9 & $17_{3 A+}-17_{2 A-}$ & 1.7 & 14.6 & d \\
\hline & 257402.2 & $18_{3 A+}-18_{2 A-}$ & 2.8 & 33.3 & e \\
\hline & 258780.4 & $19_{3 A+}-19_{2 A-}$ & 1.8 & 11.7 & \\
\hline & 259273.7 & unassigned & 1.0 & 4.7 & \\
\hline & 260381.6 & $20_{3 A+}-20_{2 A-}$ & 1.8 & 9.8 & \\
\hline & 261061.4 & $21_{-} E-20_{-5 E}$ & 0.5 & 2.7 & \\
\hline & 261704.4 & $12_{6 E}-11_{5 E}$ & 0.9 & 4.5 & \\
\hline & 261805.7 & $2_{1 E}-1_{0 E}$ & 7.3 & 34.4 & $\mathrm{f}$ \\
\hline & 262224.2 & $21_{3 A_{+}-21_{2} A_{-}}$ & 1.3 & 6.6 & \\
\hline
\end{tabular}

${ }^{\text {a }}$ Blend with ${ }^{34}$ SO 253207.

${ }^{b}$ Unresolved in laboratory.

${ }^{\mathrm{c}}$ Doublet in laboratory.

d $\mathrm{Blend}$ with $\mathrm{SO}_{2} 256247$.

${ }^{e}$ Blend with $\mathrm{CH}_{3} \mathrm{CN} 257404$.

${ }^{\mathrm{f}}$ Blend with SO 261844 .

$\mathrm{km} \mathrm{s}^{-1}$ cloud labeled the "southern condensation" by Johansson et al. (1984). The warmer component is most visible in the energetic high- $J$ lines of the $K=3^{ \pm}-2^{\mp} Q$-branches, but also manifests itself as wings on the stronger low- $J$ transitions. A simultaneous excitation analysis of all the $\mathrm{CH}_{3} \mathrm{OH}$ lines produces a rotational temperature on the order of $140 \mathrm{~K}$, but shows a trend toward higher excitation temperatures and larger line widths as the energy of the transitions increases. Fits of unconstrained Gaussian components to the methanol line shapes consistently divide the $\mathrm{CH}_{3} \mathrm{OH}$ emission into two sources characterized by velocities and line widths of 8.1 and $3.3 \mathrm{~km} \mathrm{~s}^{-1}$ for the "cool" component and 7.2 and $9.6 \mathrm{~km} \mathrm{~s}^{-1}$ for the "warm" component. Excitation temperatures for the two sources are approximately 100 and $230 \mathrm{~K}$, and the total $\mathrm{CH}_{3} \mathrm{OH}$ column density is approximately $5 \times 10^{16} \mathrm{~cm}^{-2}$. We suggest that the trends in excitation temperature noted above are due to the presence of this warmer source, which is perhaps most convincingly observed at a $v_{\mathrm{LSR}}$ of $7.0 \mathrm{~km} \mathrm{~s}^{-1}$ in torsionally excited $\mathrm{CH}_{3} \mathrm{OH}$ (Paper I). The $v_{\mathrm{LSR}}$ of the warmer component clearly shows that it is not emission from the hot core, but rather is more likely associated with quiescent molecular cloud material interacting with that from the plateau source in the vicinity of IRc 5 (Johansson et al. 1984; Blake et al. 1985).
TABLE 7

Transitions of HDO, $\mathrm{HDCO}, \mathrm{CH}_{2} \mathrm{CO}, \mathrm{HNCO}$, $\mathrm{HCOOH}$, AND $\mathrm{CH}_{3} \mathrm{CHO}^{\circ}$

\begin{tabular}{|c|c|c|c|c|c|}
\hline & $\begin{array}{c}\nu \\
(\mathrm{MHz})\end{array}$ & $\mathbf{J}_{\mathrm{K}_{\mathrm{p}} \mathrm{K}_{\mathrm{o}}}$ & $\begin{array}{r}\mathrm{T}_{\mathbf{3}}^{*} \\
(\mathrm{~K})\end{array}$ & $\begin{array}{c}\int \mathrm{T}_{\mathbf{s}}^{*} \mathrm{dv} \\
\left(\mathrm{K} \mathrm{km} \mathrm{s} \mathrm{s}^{-1}\right)\end{array}$ & notes \\
\hline HDO.......... & 255050.3 & $5_{2,3}-4_{3,2}$ & 2.1 & 8.3 & \\
\hline HDCO......... & $\begin{array}{l}256585.3 \\
257748.8 \\
258071.0 \\
259034.9\end{array}$ & $\begin{array}{l}4_{0,4}-3_{0,3} \\
4_{2,3}-3_{2,2} \\
4_{3,2}-3_{3,1} \\
4_{2,2}-3_{2,1}\end{array}$ & $\begin{array}{l}1.8 \\
0.6 \\
0.3 \\
0.6\end{array}$ & $\begin{array}{r}11.6 \\
2.3 \\
0.9 \\
2.7\end{array}$ & a \\
\hline $\mathrm{CH}_{2} \mathrm{CO} \ldots \ldots$. & $\begin{array}{l}260192.0 \\
262548.4\end{array}$ & $\begin{array}{l}13_{1,13}-12_{1,12} \\
13_{0,13}-12_{0,12}\end{array}$ & $\begin{array}{l}0.6 \\
0.5\end{array}$ & $\begin{array}{l}3.6 \\
1.9\end{array}$ & \\
\hline HNCO........ & 262769.5 & $12_{1,12}-11_{1,11}$ & 1.3 & 6.9 & b \\
\hline НСOOH..... & $\begin{array}{l}257975.0 \\
262103.5\end{array}$ & $\begin{array}{l}12_{1,12}-11_{1,11} \\
12_{0,12}-11_{0,11}\end{array}$ & $\begin{array}{l}0.3 \\
0.4\end{array}$ & $\begin{array}{l}0.9 \\
1.5\end{array}$ & \\
\hline $\mathrm{CH}_{3} \mathrm{CHO} \ldots .$. & $\begin{array}{l}255377.6 \\
260536.8 \\
262996.5 \\
\end{array}$ & $\begin{array}{l}13_{1,12}-12_{1,11} \\
14_{1,14}-13_{1,13} \\
14_{0,14}-13_{0,13}\end{array}$ & $\begin{array}{r}\cdots \\
\ldots \\
\leq 0.2 \\
\end{array}$ & $\begin{array}{l}\cdots \\
\cdots \\
\cdots\end{array}$ & $\begin{array}{l}\mathrm{c} \\
\mathrm{d}\end{array}$ \\
\hline
\end{tabular}

${ }^{\text {a }}$ Blend with $\mathrm{H}^{13} \mathrm{CN} 258157$.

b Blend with $\mathrm{CH}_{3} \mathrm{OCH}_{3} 262770,262774$.

c Buried under OCS 255375.

d Buried under SiO 260518.

\section{f) $\mathrm{HDO}, \mathrm{HDCO}, \mathrm{CH}_{2} \mathrm{CO}, \mathrm{HCOOH}$, and $\mathrm{CH}_{3} \mathrm{CHO}$}

Deuterated versions of the stable and abundant water (HDO) and formaldehyde (HDCO) molecules have been detected near 255 and $257 \mathrm{GHz}$ and are listed in Table 7. The HDCO lines are narrow $\left(\Delta v \sim 4.0 \mathrm{~km} \mathrm{~s}^{-1}\right)$ and seem to arise mainly from extended spike material $\left(v_{\mathrm{LSR}} \sim 8.8 \mathrm{~km} \mathrm{~s}^{-1}\right)$, and while the only HDO line detected also has detectable spike emission, it originates predominantly from the hot core (Olofsson 1984; Paper I). The range of energies detected in HDCO imply a (poorly determined and most likely subthermal) excitation temperature of $40 \mathrm{~K}$ and a $\mathrm{HDCO} / \mathrm{H}_{2} \mathrm{CO}$ ratio of $\sim 0.01$, typical of the strong fractionation visible in a number of other neutral molecules in Orion such as HDO and DCN.

Ketene $\left(\mathrm{CH}_{2} \mathrm{CO}\right)$ and isocyanic acid $(\mathrm{HNCO})$ were both detected in several transitions in Paper I, but because of their nearly linear character have only one line each available in the more limited frequency range searched here (see Table 7). The strengths of these lines are consistent with the excitation temperature of $120 \mathrm{~K}$ and the column density of approximately $5 \times 10^{14}$ derived previously for both $\mathrm{CH}_{2} \mathrm{CO}$ and HNCO.

The tentative detection of formic acid $(\mathrm{HCOOH})$ in Paper I is supported here by the identification of the $K_{p}=0$ and $K_{p}=1$ members of the $J=12-11$ band listed in Table 7. The widths of these lines $\left(\Delta v \sim 3.8 \mathrm{~km} \mathrm{~s}^{-1}\right)$ are slightly smaller than those in Paper I, but the $v_{\text {LSR }}$ of $8.0 \mathrm{~km} \mathrm{~s}^{-1}$ is nearly identical with the lower frequency value. The estimated column density is still $\sim 10^{14}$ for an assumed rotational temperature of $90 \mathrm{~K}$.

Acetaldehyde $\left(\mathrm{CH}_{3} \mathrm{CHO}\right)$ has been searched for in several transitions, but only upper limits have been obtained. Predicted frequencies for the $\mathrm{CH}_{3} \mathrm{CHO}$ E-symmetry species are not available at present, so only the A-symmetry lines are listed in Table 7. The derived upper limits are on the order of $5 \times 10^{13}$, 
consistent with our earlier results (Blake et al. 1984). Thus, the presence of acetaldehyde in Orion is still rather uncertain.

\section{g) $\mathrm{SO}_{2}$}

As noted in Paper I, emission from $\mathrm{SO}_{2}$ produces by itself about $28 \%$ of the total integrated flux from molecular lines in Orion. The large number and great strength of the $\mathrm{SO}_{2}$ lines listed in Table 8 are primarily responsible, along with $\mathrm{SO}$, for the large integrated flux from spectral line emission noted in $\S \mathrm{I}$. The $\mathrm{SO}_{2}$ line shape is quite broad and, like $\mathrm{SO}$, is composed predominantly of plateau emission with less than $2 \%$ of the integrated flux originating in the extended molecular cloud. The average ${ }^{32} \mathrm{SO}_{2}$ width is $30.2 \mathrm{~km} \mathrm{~s}^{-1}$, while that of ${ }^{34} \mathrm{SO}_{2}$ is about $25.2 \mathrm{~km} \mathrm{~s}^{-1}$. Both species have a peak $v_{\mathrm{LSR}}$ of approximately $7.7 \mathrm{~km} \mathrm{~s}^{-1}$.

Ratios of the ${ }^{32} \mathrm{~S} /{ }^{34} \mathrm{~S}$ line profiles indicate that for the strongest lines the $\mathrm{SO}_{2}$ emission is only marginally saturated and becomes optically thin for velocity offsets greater than approximately $15 \mathrm{~km} \mathrm{~s}^{-1}$. The strengths of the optically thin line wings and other weaker lines which should be optically thin at all velocities imply an excitation temperature of $100 \mathrm{~K}$ and a column density of $5 \times 10^{16}$, but hotter gas is evident as well (Schloerb et al. 1983; Paper I). For example, the highest energy lines, including the $14_{0,14}-13_{1,13}$ and $22_{2,24}-22_{2,23}$ vibrationally excited lines tentatively detected at 243523 and $257420 \mathrm{MHz}$, suggest a rotational temperature of $\gtrsim 175 \mathrm{~K}$. The vibrationally excited emission has a poorly determined $v_{\text {LSR }}$ of $5.0 \mathrm{~km} \mathrm{~s}^{-1}$, possibly indicative of emission from the hot core. The $\mathrm{SO}_{2}$ measurements provide our best limits on the total amount of material in the plateau source. Following the procedure of Kuiper, Zuckerman, and Rodriguez-Kuiper (1981), we estimate that the plateau has an $\mathrm{H}_{2}$ column density of $\lesssim 5 \times 10^{22} \mathrm{~cm}^{-2}$, in agreement with the recent interferometer $2.6 \mathrm{~mm}$ continuum maps of Masson et al. (1985).

TABLE 8

Transitions OF $\mathrm{SO}_{2}$

\begin{tabular}{cccccc}
\hline \hline & $\begin{array}{c}\nu \\
(\mathrm{MHz})\end{array}$ & $\mathrm{J}_{\mathrm{K}_{\mathrm{p}} \mathrm{K}_{\mathrm{o}}}$ & $\begin{array}{c}\mathrm{T}_{\mathrm{z}}^{*} \\
(\mathrm{~K})\end{array}$ & $\begin{array}{c}\int \mathrm{T}_{\mathrm{a}}^{*} \mathrm{dv} \\
\left(\mathrm{K} \mathrm{km} \mathrm{s}^{-1}\right)\end{array}$ & notes \\
\hline $\mathrm{SO}_{2} \ldots \ldots \ldots \ldots \ldots$. & 248057.4 & $15_{2,14}-15_{1,15}$ & 6.1 & 154. & \\
& 248436.9 & $13_{3,11}-14_{0,14}$ & 0.6 & 8.0 & $\mathrm{a}$ \\
& 255553.3 & $4_{3,1}-4_{2,2}$ & 7.4 & 168. & \\
& 255595.3 & $51_{7,45}-50_{8,42}$ & $0.4 ?$ & $2.7 ?$ & $\mathrm{~b}$ \\
& 255958.1 & $3_{3,1}-3_{2,2}$ & 3.5 & 86.8 & \\
& 256247.0 & $5_{3,3}-5_{2,4}$ & 6.5 & 158. & \\
& 257100.0 & $7_{3,5}-7_{2,6}$ & 7.9 & 205. & \\
& 258388.8 & $32_{4,28}-32_{3,29}$ & 1.5 & 25.1 & \\
& 258667.0 & $20_{7,13}-21_{6,16}$ & 0.7 & 6.8 & \\
& 258942.2 & $9_{3,7}-9_{2,6}$ & 6.7 & 173. & \\
& 259599.5 & $30_{4,26}-30_{3,27}$ & 1.5 & 19.8 & \\
& 262256.9 & $11_{3,9}-11_{2,10}$ & 5.9 & 141. & \\
$\mathrm{SO}_{2}\left(\nu_{2}=1\right) \ldots \ldots .$. & 257420.5 & $24_{2,22}-24_{2,23}$ & 0.4 & 1.4 & \\
& & & & & \\
${ }^{34} \mathrm{SO}_{2} \ldots \ldots \ldots \ldots .$. & 247440.4 & $5_{3,3}-5_{2,4}$ & 0.7 & 5.3 & \\
& 248364.8 & $7_{3,5}-7_{2,6}$ & 0.9 & 14.3 & \\
& 250358.4 & $9_{3,7}-9_{2,8}$ & 0.9 & 23.1 & \\
& 259617.2 & $13_{3,11}-13_{2,12}$ & 1.0 & 8.3 & \\
& 260327.0 & $24_{2,22}-24_{1,23}$ & 1.0 & 6.0 & \\
\hline
\end{tabular}

a Blend with $\mathrm{C}_{2} \mathrm{H}_{5} \mathrm{CN} 248436$.

${ }^{b}$ Blend with NS 255602 ? h) $\mathrm{HCOOCH}_{3}$ and $\mathrm{CH}_{3} \mathrm{OCH}_{3}$

While $\mathrm{SO}_{2}$ provides the most flux from any single species, the largest number of transitions in this survey belong to the methyl formate $\left(\mathrm{HCOOCH}_{3}\right)$ molecule. The heavy nature of this species coupled with the rotational line splittings induced by internal rotation of the methyl group with respect to the HCOO backbone creates scores of transitions spread rather evenly throughout the millimeter-wave region. In support of our Orion surveys, Plummer et al. $(1984,1985)$ have recently investigated the rotational spectrum of the A- and E-symmetry states of methyl formate to produce a highly accurate map of the $\mathrm{HCOOCH}_{3}$ transition frequencies up to $500 \mathrm{GHz}$. Most of our detected lines, listed in Table 9, have been measured directly, but for consistency we have used the predicted frequencies here. Over 175 lines have been used to derive an average $\mathrm{HCOOCH}_{3} v_{\text {LSR }}$ and $\Delta v$ of 7.9 and $3.9 \mathrm{~km} \mathrm{~s}^{-1}$ in Orion, and also to verify the rotational temperature and column density of $90 \mathrm{~K}$ and $3 \times 10^{15} \mathrm{~cm}^{-2}$ found in Paper $\mathrm{I}$.

$\mathrm{HCOOCH}_{3}$ is probably produced chemically from methanol in dense interstellar clouds, and is therefore likely to be present in the warm $\mathrm{CH}_{3} \mathrm{OH}$ component noted in $\S \mathrm{III} e$. Emission from the first torsionally excited state of methyl formate should be detectable in this material because of the low energy of the torsional motion in $\mathrm{HCOOCH}_{3}(\sim 100$ $\mathrm{cm}^{-1}$ ), but to our knowledge no estimates of the torsionally excited $\mathrm{HCOOCH}_{3}$ rotational constants have been made.

Dimethyl ether $\left(\mathrm{CH}_{3} \mathrm{OCH}_{3}\right)$ is another abundant internal rotor which has been detected through the 15 rotational transitions listed in Table 9. Unlike $\mathrm{HCOOCH}_{3}$, dimethyl ether has two internal rotors, and each rotational transition is therefore split into four components corresponding to the allowed products of the A- and E-symmetry states of the individual $\mathrm{CH}_{3}$ rotors. For the most part we resolve these splittings even with our $1 \mathrm{MHz}$ filters. The average velocity and line width of the $\mathrm{CH}_{3} \mathrm{OCH}_{3}$ emission are 7.9 and 3.6 $\mathrm{km} \mathrm{s}^{-1}$, respectively, which are very similar to those of both $\mathrm{CH}_{3} \mathrm{OH}$ and $\mathrm{HCOOCH}_{3}$. In addition, the derived rotational temperature and column density of $80 \mathrm{~K}$ and $3 \times 10^{15} \mathrm{~cm}^{-2}$ are the same, within errors, as those of $\mathrm{HCOOCH}_{3}$. These results may indicate that $\mathrm{CH}_{3} \mathrm{OH}, \mathrm{HCOOCH}_{3}$, and $\mathrm{CH}_{3} \mathrm{OCH}_{3}$ are intimately related chemically in the interstellar medium. A more detailed argument supporting this proposition will be presented elsewhere (Blake et al. 1985).

\section{i) $\mathrm{C}_{2} \mathrm{H}_{3} \mathrm{CN}$ and $\mathrm{C}_{2} \mathrm{H}_{5} \mathrm{CN}$}

Vinyl cyanide $\left(\mathrm{C}_{2} \mathrm{H}_{3} \mathrm{CN}\right)$ and ethyl cyanide $\left(\mathrm{C}_{2} \mathrm{H}_{5} \mathrm{CN}\right)$ are hydrogenated versions of the abundant cyanoacetylene $\left(\mathrm{HC}_{3} \mathrm{~N}\right)$ molecule with very dense rotational spectra because of their heavy, asymmetric structure. Like cyanoacetylene, they show strong emission from the hot core, but unlike $\mathrm{HC}_{3} \mathrm{~N}$ they do not appear to be present in measurable quantities in either the spike or the plateau sources. Because of the high excitation in the hot core, lines up to $J=29$ are easily visible in Figure 1 from both $\mathrm{C}_{2} \mathrm{H}_{3} \mathrm{CN}$ and $\mathrm{C}_{2} \mathrm{H}_{5} \mathrm{CN}$, and are listed in Table 10 . The average $v_{\mathrm{LSR}}$ and $\Delta v$ for the vinyl and ethyl cyanide transitions are quite similar, namely, 5.0 and $11.4 \mathrm{~km} \mathrm{~s}^{-1}$, respectively. The rotational temperatures are also equivalent, within errors, at $150 \mathrm{~K}$, but ethyl cyanide is an 
TABLE 9

TraNSITIONS OF $\mathrm{HCOOCH}_{3}$ AND $\mathrm{CH}_{3} \mathrm{OCH}_{3}$

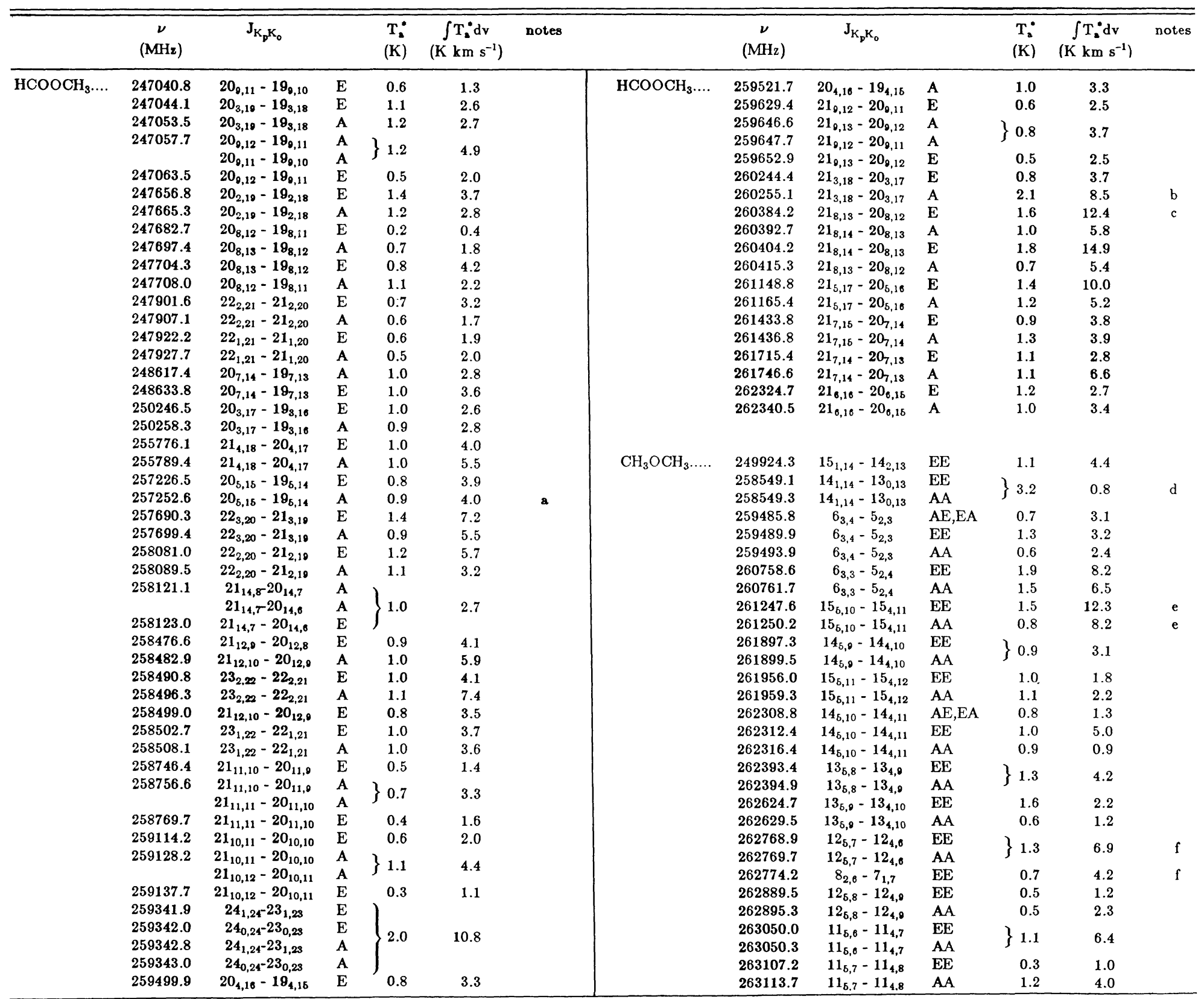

${ }^{a}$ Blend with $\mathrm{C}_{2} \mathrm{H}_{5} \mathrm{CN} 257227,{ }^{30} \mathrm{SiO} 257255$.

${ }^{b}$ Blend with $\mathrm{H}^{13} \mathrm{CO}^{+} 260255$.

${ }^{\mathrm{d}}$ Blend with $\nu_{8}=1 \mathrm{CH}_{3} \mathrm{CN} 258552$

c Blend with $\mathrm{CH}_{3} \mathrm{OH} 260382$

Blend with HNCO 262769. 
TABLE 10

Transitions of $\mathrm{C}_{2} \mathrm{H}_{3} \mathrm{CN}$ and $\mathrm{C}_{2} \mathrm{H}_{5} \mathrm{CN}$

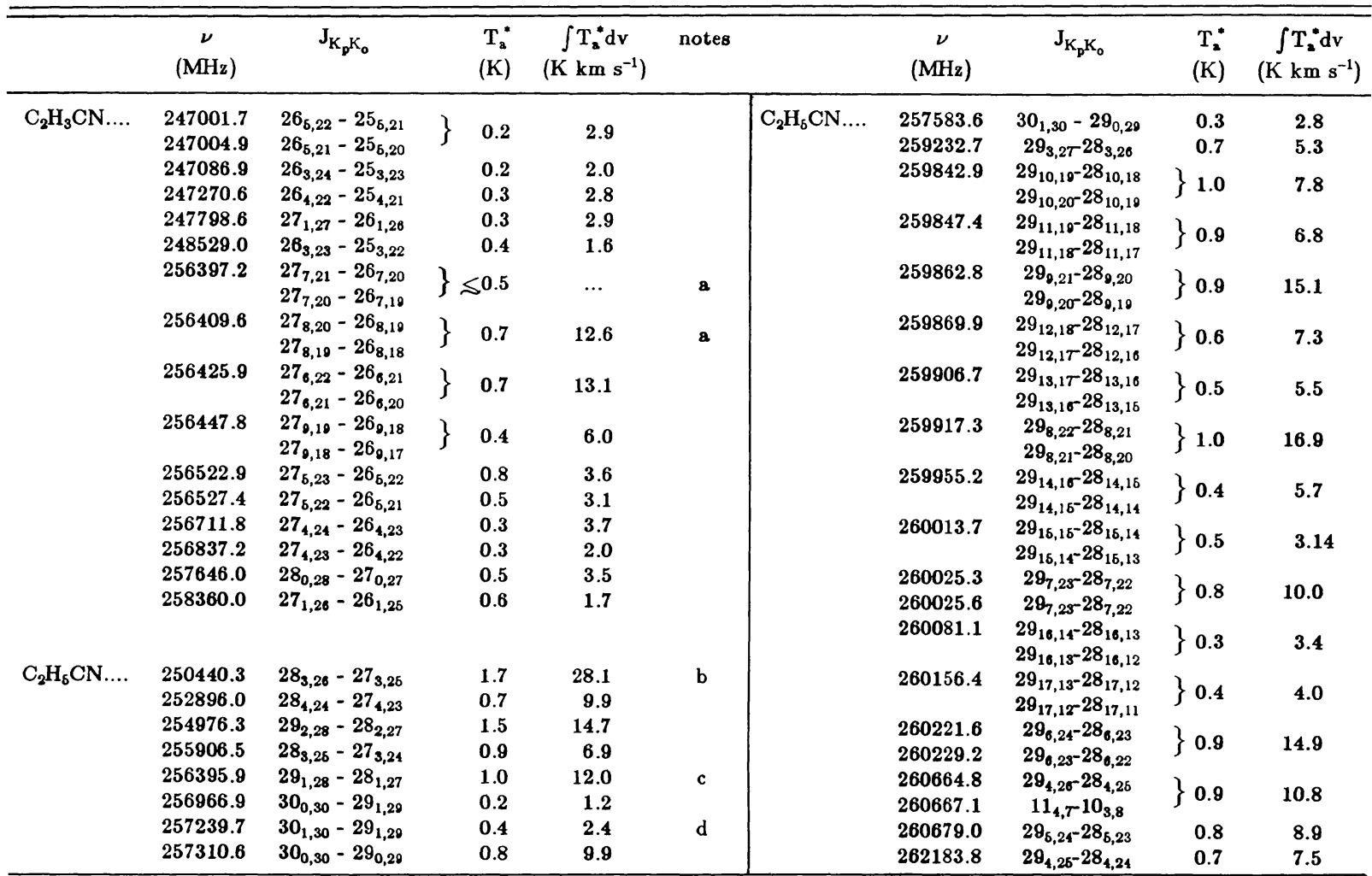

a Blend with $\mathrm{C}_{2} \mathrm{H}_{5} \mathrm{CN} 256394$

${ }^{b}$ Blend with NO 250437, 250440, 250448.

${ }^{c}$ Blend with $\mathrm{C}_{2} \mathrm{H}_{3} \mathrm{CN} 256397$.

${ }^{\mathrm{d}}$ Blend with ${ }^{29} \mathrm{SiO} 257255$.

order of magnitude more abundant. The derived column densities are the same as in Paper I, namely, $2 \times 10^{14}$ for $\mathrm{C}_{2} \mathrm{H}_{3} \mathrm{CN}$ and $2 \times 10^{15} \mathrm{~cm}^{-2}$ for $\mathrm{C}_{2} \mathrm{H}_{5} \mathrm{CN}$. The great difficulty of hydrogenating cyanopolyacetylene ions in the gas phase (Herbst, Adams, and Smith 1983) and the presence of vinyl cyanide and ethyl cyanide only in the hot core has led a number of investigators to conclude that the hydrogenated species are most likely produced on grain surfaces and then released into the gas phase (Watson 1976; Irvine and Hjalmarson 1984).

\section{j) Unidentified Lines}

A total of 16 lines are currently unidentified in the spectrum between 247 and $263 \mathrm{GHz}$. The frequencies, widths, and peak antenna temperatures of these lines are presented in Table 11. The original double-sideband data have been consulted to ensure that each of the lines in Table 11 is real, and not the ghost of features from the opposite sideband.

We note that the initially unidentified line in our lower frequency survey at $217823 \mathrm{MHz}$ (Paper I) has now been attributed to a blend of the $6_{06} \rightarrow 5_{15}$ and $6_{16} \rightarrow 5_{05}$ transitions of the $\mathrm{C}_{3} \mathrm{H}_{2}$ cyclopropenylidene radical by Thaddeus (1985). Presumably, other lines of this highly asymmetric and reactive species may account for some of the unidentified features in
TABLE 11

UNIDENTIFIED TRANSITIONS

\begin{tabular}{lccc}
\hline \hline & $\begin{array}{c}\text { Frequency } \\
(\mathrm{MHz})\end{array}$ & $\begin{array}{c}\mathrm{T}_{\mathrm{a}}^{*} \\
(\mathrm{~K})\end{array}$ & $\begin{array}{r}\text { FWHM } \\
\left(\mathrm{km} \mathrm{s}^{-1}\right)\end{array}$ \\
\hline unidentified.... & $\mathbf{2 4 7 4 6 9}$ & 0.6 & 3.0 \\
& 247630 & 0.4 & 3.7 \\
& 247636 & 0.4 & 4.5 \\
& 247875 & 0.7 & 2.7 \\
& 247911 & 0.5 & 1.8 \\
& 255651 & 1.2 & 21.9 \\
& 257912 & 1.0 & 4.7 \\
& 259285 & 0.8 & 11.1 \\
& 259311 & 0.6 & 4.5 \\
& 259690 & 0.5 & 3.6 \\
& 259733 & 0.7 & 3.3 \\
& 259986 & 0.8 & 6.8 \\
& 260440 & 1.2 & 3.7 \\
& 260726 & 1.2 & 7.5 \\
& 261564 & 1.1 & 8.0 \\
& 263065 & 0.9 & 1.6 \\
\hline
\end{tabular}

our Orion emission-line surveys, but no detailed frequency predictions are currently available.

As described in $\S \mathrm{II} b$, the spectrum is generally freer of artifacts associated with the data reduction than in Paper I, owing to changes in the data collection procedure. The only false features clearly present in the spectrum are a narrow line 
at $248080 \mathrm{MHz}$ and broad features at 255283 and 261360 $\mathrm{MHz}$.

\section{k) Other Species}

Two species identified at lower frequencies, the formyl radical $(\mathrm{HCO})$ and methylamine $\left(\mathrm{CH}_{3} \mathrm{NH}_{2}\right)$, have not been convincingly detected in the $215-263 \mathrm{GHz}$ range. Johansson et al. (1984) tentatively detected the strongest component of the $N=1-0 \mathrm{HCO}$ multiplet at a level of $0.05 \mathrm{~K}$ in their survey of Orion, and to verify this work we have carefully searched for the fine and hyperfine components of the $N=3-2$ transition near $260.1 \mathrm{GHz}$ (Blake, Sastry, and De Lucia 1984). Unfortunately, the $J=7 / 2-5 / 2, F=3-2$ and $J=5 / 2-3 / 2$, $F=2-1$ lines are buried beneath two $\mathrm{C}_{2} \mathrm{H}_{5} \mathrm{CN}$ transitions and are not observable. The remaining hyperfine components are in a cleaner region of the spectrum, but have antenna temperatures of less than $0.2 \mathrm{~K}(3 \sigma)$, which imply an excitation temperature of less than $10 \mathrm{~K}$ if the line ascribed to $\mathrm{HCO}$ by Johansson et al. (1984) is correct. Although this value is quite low, a highly subthermal rotational temperature has been derived for HCO ( $\mu_{a}=1.36$ debye; Landsberg, Merer, and Oka 1977) in NGC 2024 by Snyder, Schenewerk, and Hollis (1985).

Methylamine $\left(\mathrm{CH}_{3} \mathrm{NH}_{2}\right)$ was initially detected in Orion at 86.1 and $88.7 \mathrm{GHz}$ by Kaifu et al. (1974) and Kutner et al. (1980). However, neither of these transitions were detected by Johansson et al. (1984), and it therefore seems desirable to check these results at higher frequencies. The millimeter-wave spectrum of methylamine is quite complicated because it contains splittings from both the internal rotation of the $\mathrm{CH}_{3}$ group and inversion of the $\mathrm{NH}_{2}$ fragment. In the absence of any predicted frequencies above $100 \mathrm{GHz}, \mathrm{K}$. V. L. N. Sastry has kindly provided us with a list of measured frequencies for methylamine in the $200-300 \mathrm{GHz}$ region. No strong lines occur in the present survey, but the $J=5-4$ transitions are accessible in the lower frequency work, as they occur near 222 $\mathrm{GHz}$. We find no indication of emission at any of the more than 10 low-lying transitions in the $222 \mathrm{GHz}$ region. Our upper limits confirm the negative results of Johansson et al. and imply that the identification of $\mathrm{CH}_{3} \mathrm{NH}_{2}$ in Orion must be regarded as highly speculative.

Recombination lines are relatively unimportant at high frequencies owing to their infrequent occurrence and their low intensity compared with molecular emission features. The $\mathrm{H} 29 \alpha$ line at $256302.5 \mathrm{MHz}$ is possibly present, although it is crowded in with a band of $\mathrm{CH}_{3} \mathrm{CCH}$ lines. As in Paper I, the weaker $\mathrm{H} \beta$ and $\mathrm{He} \alpha$ lines (here $\mathrm{H} 36 \beta$ and $\mathrm{He} 29 \alpha$ ) are not detected.

Finally, the remarkable isomeric selectivity found in Orion by Johansson et al. (1984) and in Paper I is further strengthened here. Whereas dimethyl ether and methyl formate are easily detectable and quite abundant for molecules of such complexity, the isomerically related $\mathrm{C}_{2} \mathrm{H}_{5} \mathrm{OH}$ and
$\mathrm{CH}_{3} \mathrm{COOH}$ species have not been identified. As noted in $\S$ III $h$, this most likely arises because of the intimate chemical relationship between $\mathrm{CH}_{3} \mathrm{OCH}_{3}, \mathrm{HCOOCH}_{3}$, and their highly abundant precursor, $\mathrm{CH}_{3} \mathrm{OH}$.

\section{SUMMARY}

The Owens Valley survey of Orion now covers a $48 \mathrm{GHz}$ interval and contains a total of 787 lines from 29 molecules, dramatically illustrating the usefulness of molecular rotational emission in determining the chemical and physical nature of molecular clouds. Emission from the six terrestrially stable molecules $\mathrm{SO}_{2}, \mathrm{CH}_{3} \mathrm{OH}, \mathrm{CH}_{3} \mathrm{CN}, \mathrm{C}_{2} \mathrm{H}_{5} \mathrm{CN}, \mathrm{HCOOCH}_{3}$, and $\mathrm{CH}_{3} \mathrm{OCH}_{3}$ provides nearly three-quarters of the detected features, while over $70 \%$ of the integrated flux from molecular lines is concentrated in the large line-width plateau components of $\mathrm{CO}, \mathrm{CS}, \mathrm{SO}$, and $\mathrm{SO}_{2}$. Thus, a small number of species dominate the millimeter-wave spectrum of Orion.

Somewhat surprisingly, over $96 \%$ of the detected lines may be attributed to well-known interstellar molecules. In fact, the number of species identified in Orion has actually decreased as the results of this survey have supplanted earlier exploratory work in the near-millimeter-wave region. Of the remaining unidentified lines, it is probably safe to say that at least some of them are due to the states of currently identified molecules whose spectra have not been characterized above $200 \mathrm{GHz}$.

Indeed, it has become clear during the course of this work that a great deal of laboratory work will be necessary before a full examination of the chemical composition of the interstellar medium may be attempted. Even for the intermediate frequencies at which the present survey was conducted, only a dedicated combination of laboratory spectroscopy and theoretical predictions has allowed the majority of transitions from known molecules to be assigned. Line searches in the higher frequency submillimeter region, in which the fundamental transitions of new species such as the potentially important molecular hydrides may be found, will become increasingly hampered by the limited amount of laboratory data, but may now be efficiently conducted because of the availability of accurate large-aperture telescopes and sensitive high-frequency receivers such as those which have made this survey possible.

The authors are especially grateful to F. C. De Lucia, E. Herbst, G. M. Plummer, F. J. Lovas, and H. M. Pickett for undertaking the large body of supporting laboratory work necessary for the successful completion of the Orion surveys, and for allowing us to use their spectra line catalogs. We would also like to thank D. P. Woody and S. L. Scott for their efforts in ensuring successful observations, and R. E. Miller of AT\&T Bell Laboratories, Murray Hill, for supplying the junctions used in this work. Single-dish millimeter-wave astronomy at the Owens Valley Radio Observatory is supported by NSF grants AST-8214693 and 8311849.

\section{REFERENCES}

Blake, G. A., and Pickett, H. M. 1985, unpublished.

Blake, G. A., Sastry, K. V. L. N., and De Lucia, F. C. 1984, J. Chem. Phys., 80, 95

Blake, G. A., Sutton, E. C., Masson, C. R., and Phillips, T. G. 1985, in preparation.
Blake, G. A., Sutton, E. C., Masson, C. R., Phillips, T. G., Herbst, E., Plummer, G. M., and De Lucia, F. C. 1984, Ap. J., 286, 586. Cummins, S. E., Linke, R. A., and Thaddeus, P. 1986, Ap. J. Suppl., in press.

Friberg, P. 1984, Astr. Ap., 132, 265. 
Genzel, R., Downes, D., Ho, P. T. P., and Bieging, J. 1982, Ap. J. (Letters), 259, L103.

I Gottlieb, C. A., Ball, J. A., Gottlieb, E. W., Lada, C. J., and Penfield, H. 1975, Ap. J. (Leters), 200, L147.

Herbst, E., Adams, N. G., and Smith, D. 1983, Ap. J., 269, 329.

, Herbst, E., Messer, J. K., De Lucia, F. C., and Helminger, P. 1984, J. IOI Molec. Spectrosc., 108, 42.

IrI Irvine, W. M., and Hjalmarson, A. 1984, in Origins of Life (Dordrecht: Reidel), pp. 15-23.

Johansson, L. E. B., et al. 1984, Astr. Ap., 130, 227.

Kaifu, N., Morimoto, M., Nagane, K., Akabane, K., Iguchi, T., and Takagi, K. 1974, Ap. J. (Letters), 191, L135.

Kuiper, T. B. H., Zuckerman, B., Kakar, R. K., and Rodriguez-Kuiper, E. N. 1975, Ap. J. (Letters), 200, L151.

Kuiper, T. B. H., Zuckerman, B., and Rodriguez-Kuiper, E. N. 1981, Ap. J., 251, 88.

Kutner, M. L., Machnik, D. E., Tucker, K. D., and Dickman, R. L. 1980, Ap. J., 242, 541 .

Landsberg, B. M., Merer, A. J., and Oka, T. 1977, J. Molec. Spectrosc., 67,459 .

Loren, R. B., and Mundy, L. E. 1984, Ap. J., 286, 232.

Masson, C. R. 1982, Astr. Ap., 114, 270.

Masson, C. R., Claussen, M. J., Lo, K. Y., Moffet, A. T., Phillips, T. G., Sargent, A. I., Scott, S. L., and Scoville, N. Z. 1985, Ap. J. (Letters), 295, L47.
Morris, M., Palmer, P., and Zuckerman, B. 1980, Ap. J., 237, 1.

Olofsson, H. 1984, Astr. Ap., 134, 36.

Plummer, G. M., Herbst, E., De Lucia, F. C., and Blake, G. A. 1984, Ap. J. Suppl., 55, 633.

1985, Ap. J. Suppl., submitted.

Poynter, R. L., and Pickett, H. M. 1984, Submillimeter, Millimeter, and Microwave Spectral Line Catalogue, JPL Pub. 80-23, Rev. 2.

Sastry, K. V. L. N., et al. 1985, in preparation.

Sastry, K. V. L. N., Helminger, P., Charo, A., Herbst, E., and De Lucia, F. C. 1982, Ap. J. (Letters), 251, L119.

Schloerb, F. P., Friberg, P., Hjalmarson, Å., Höglund, B., and Irvine, W. M. 1983, Ap. J., 264, 161.

Snyder, L. E., Schenewerk, M. J., and Hollis, J. M. 1985, Ap. J., 298, 360.

Sutton, E. C. 1983, IEEE Trans., MTT-31, 589.

Sutton, E. C., Blake, G. A., Masson, C. R., and Phillips, T. G. 1984, Ap. J. ( Letters), 283, L41. 1985, Ap. J. Suppl., 58, 341 (Paper I).

Thaddeus, P. 1985 , private communication.

Watson, W. D. 1976, Rev. Mod. Phys., 48, 513.

Wootten, A., Loren, R. B., and Bally, J. 1984, Ap. J., 277, 189.

Ziurys, L. M., Saykally, R. J., Plambeck, R. L., and Erickson, N. R. 1982, Ap. J., 254, 94.

Zuckerman, B., and Palmer, P. 1975, Ap. J. (Letters), 199, 235.

Geoffrey A. Blake and E. C. Sutton: Space Sciences Laboratory, University of California, Berkeley, CA 94720

C. R. MASSON: Downs Laboratory of Physics, 405-47, California Institute of Technology, Pasadena, CA 91125

T. G. PHILlips: Downs Laboratory of Physics, 320-47, California Institute of Technology, Pasadena, CA 91125 